\title{
Proteomic cellular signatures of kinase inhibitor-induced cardiotoxicity: Mount Sinai DToxS LINCS Center Dataset
}

\author{
Yuguang Xiong a, \#, Tong Liu ${ }^{b, \#, ~ T o n g ~ C h e n ~}{ }^{b, \#, ~ J e n s ~ H a n s e n ~}{ }^{a}, \mathrm{Bin} \mathrm{Hu}^{a}$, \\ Yibang Chen ${ }^{a}$, Gomathi Jayaraman ${ }^{a}$, Stephan Schürer ${ }^{e, f}$, Dusica Vidovic ${ }^{e, f}$, \\ Joseph Goldfarb ${ }^{a}$, Eric A. Sobie ${ }^{a}$, Marc R. Birtwistle ${ }^{a, c}$, \\ Ravi lyengar ${ }^{a,}{ }^{*}$, Hong $\mathrm{Li}^{b,{ }^{*}}$ and Evren U. Azeloglu ${ }^{a, d,{ }^{*}}$
}

${ }^{a}$ Department of Pharmacological Sciences and Institute for Systems Biomedicine, Icahn School of Medicine at Mount Sinai, New York, NY 10029

${ }^{b}$ Center for Advanced Proteomics Research and Department of Microbiology, Biochemistry and Molecular Genetics, Rutgers University - New Jersey Medical School, Newark, NJ 07103

${ }^{c}$ Department of Chemical and Biomolecular Engineering, Clemson University, Clemson, SC 29634

${ }^{d}$ Department of Medicine, Division of Nephrology, Icahn School of Medicine at Mount Sinai, New York, NY 10029

e Department of Molecular and Cellular Pharmacology, Miller School of Medicine, University of Miami, Miami, FL 33136

${ }^{f}$ Center for Computational Science, University of Miami, Miami, FL 33136

\# Equal contributions

${ }^{*}$ Address for correspondence:

Evren U. Azeloglu, Department of Medicine, Division of Nephrology, Icahn School of Medicine at Mount Sinai. New York, NY 10029. Tel: (212) 241-8519, Fax: (212) 987-0389, Email: evren.azeloglu@mssm.edu

or

Hong Li, Department of Microbiology, Biochemistry and Molecular Genetics, Rutgers University - NJMS, Newark, NJ 07103. Tel: 973-972-8396, Fax: 973-972-1865, E-Mail: liho2@rutgers.edu or

Ravi lyengar, Department of Pharmacological Sciences, Icahn School of Medicine at Mount Sinai, New York, NY 10029. Tel: (212) 659-1700, Fax: (212) 831-0114 


\section{Abstract}

The Drug Toxicity Signature Generation Center (DToxS) at the Icahn School of Medicine at Mount Sinai is one of the centers of the NIH Library of Integrated Network-Based Cellular Signatures (LINCS) program. A key aim of DToxS is to generate both proteomic and transcriptomic signatures that can predict adverse effects, especially cardiotoxicity, of kinase inhibitors approved by the Food and Drug Administration. Towards this goal, high throughput shot-gun proteomics experiments (317 cell line/drug combinations +64 control lysates) have been conducted at the Center for Advanced Proteomics Research at Rutgers University - New Jersey Medical School. Using computational network analyses, these proteomic data can be integrated with transcriptomic signatures generated in tandem to identify cellular signatures of cardiotoxicity that may predict kinase inhibitor-induced toxicity and possible mitigation. Both raw and processed proteomics data have been carefully screened for quality and made publicly available via the PRIDE database. As such, this broad protein kinase inhibitor-stimulated cardiomyocyte proteomic data and signature set is valuable for the prediction of drug toxicities.

\section{Links to: Metadata Tables}

\begin{tabular}{|l|l|}
\hline Design Type(s) & Drug induced differential protein expression \\
\hline Measurement Type(s) & $\begin{array}{l}\text { Protein expression profiling, label-free quantification, shot-gun } \\
\text { proteomics }\end{array}$ \\
\hline Technology Type(s) & Liquid chromatography - tandem mass spectrometry \\
\hline Factor Type(s) & Treatment of cells with protein kinase inhibitors \\
\hline Sample Characteristic(s) & Homo sapiens, adult cardiomyocyte cell lines \\
\hline Machine-accessible metadata file describing the reported data (ISA-tab format) \\
\hline
\end{tabular}




\section{Background \& Summary}

Protein kinase inhibitors (KIs) are a class of targeted therapeutics that are being increasingly used in the treatments of cancer ${ }^{1}$. Their use and development have been accelerated in the recent years as they could target tumors more effectively than most other chemotherapeutics and their mechanisms of actions are well defined. In many cases, however, their intended or off-target kinases serve key biological roles, which when blocked, lead to severe adverse effects ${ }^{2}$. One of the major adverse effects that lead to $\mathrm{KI}$ discontinuation of treatment is cardiotoxicity ${ }^{3}$. As a part of the NIH Library of Integrated Cellular Signatures (LINCS) program ${ }^{4}$, the main goal of the Mount Sinai Drug Toxicity Signature Generation Center (DToxS) is to better understand mechanisms of $\mathrm{KI}$-associated cardiotoxicity by constructing cellular signatures of drug effects. Since different omics assays show varied sensitivities ${ }^{5}$ and offer complementary molecular information on the cellular phenotypic state ${ }^{6}$, in order to develop a comprehensive understanding of the cellular responses to KIs, we use network analyses ${ }^{7}$ to combine differential expression of genes and gene products in human cardiomyocytes treated by FDA approved KIs (Table 1), analyzed using both transcriptomic and proteomic methods. In this dataset, we present the proteomic portion of the effects of KIs on human cardiomyocytes.

Quantitative proteomics technologies have evolved to become increasingly effective at identifying differentially expressed proteins among diverse experimental conditions. Currently, two broad strategies are widely used for large-scale quantitative proteomics studies: stable isotope label-based ${ }^{8,9}$ and label-free ${ }^{10,11}$ quantification (LFQ) strategies. Each strategy entails trade-offs of strengths and limitations. Stable isotope label-based strategies involve labeling proteins or peptides with amino acids or chemical tags that contain stable isotopes $\left(e . g .{ }^{2} \mathrm{H},{ }^{13} \mathrm{C}\right.$, ${ }^{15} \mathrm{~N}$ or ${ }^{18} \mathrm{O}$, etc.), which provide mass shift features that are differentiated in high resolution mass spectrometers for the quantification of proteins pooled from up to a dozen biological conditions. 
Examples include Isobaric Tag for Relative and Absolute Quantitation (iTRAQ), Tandem Mass Tag (TMT) and Stable Isotope Labeling with Amino acids in Cell culture (SILAC). Key benefits of the label-based proteomics strategy over LFQ methods include the minimization of experimental variations and the maximization of protein quantitation precisions ${ }^{12,13}$. In contrast, two key factors limit the wide applications of the label-based strategies for clinically relevant proteomics studies of hundreds of samples: commercially available stable isotope proteomics reagents can currently accommodate the simultaneous quantification of up to 11 samples; and the costs for label-based proteomics reagents are prohibitively expensive for analyzing hundreds of samples. Compared to label-based proteomics strategies, LFQ methods do not involve expensive labeling reagents, thus they can be used for clinically relevant studies of hundreds and thousands of samples, if proper controls and quality guidelines are followed. The most widely used LFQ strategies utilize either the peptide mass spectral ion intensities or tandem mass spectral counts to approximate the abundances of proteins and compare them across many samples. Also, LFQ methods offer additional benefits over label-based strategies, including quantification with wider dynamic ranges and more flexibility in study design ${ }^{14-16}$. When compared to label-based strategies, the trade-offs for the LFQ methods are well known: results may contain larger variability in quantification and smaller number of proteins quantified. Larger quantification variability can originate from the fact that in a LFQ workflow, each sample is analyzed independently, including proteolytic digestion and LC/MS/MS analysis, which can introduce additive technical variations at each experimental step. These analytical inconsistencies can be minimized by omitting multi-dimensional peptide fractionations; however, while LFQ sample throughput can be increased through this approach, it should be noted that this approach can also lead to a smaller number of identified proteins. 
In this DToxS dataset, we've chosen the LFQ method in order to economically compare the proteomics signatures from over 300 samples that have been collected over an extended period of time, some with limited protein yields. The transcriptome of these samples have been previously assessed using the 3' digital gene expression RNA sequencing (RNAseq) ${ }^{17}$; to ensure both proteomics and RNAseq data can be compared from the same drug-treated cells (see example use case below), we've optimized a method to extract proteins from the samples after RNA extraction (Fig. 1). All the sample preparation, analysis procedures and data have gone through careful quality control steps to ensure reproducibility (Fig. 2); standard operating procedures and data descriptors are publicly available in the DToxS website (www.dtoxs.org) and both raw and MaxQuant-analyzed data are publicly available via PRIDE (with the proteome exchange ID of PXD014791) as well as the LINCS Project data portals (http://lincsportal.ccs.miami.edu/dcic-portal/). We think that this large $\mathrm{KI}$-induced proteomics dataset will be a valuable resource for the cancer, cardiology and drug development communities. 


\section{Methods}

\section{Cell culture, drug treatments and RNA extraction}

Detailed materials and methods for all the experiments in this study can be accessed as version- and quality-controlled standard operating procedures on DToxS.org. Briefly, four commercially available cell lines of primary adult human cardiomyocytes were purchased from PromoCell GmbH (Cat \#: C12810; Heidelberg, Germany), expanded and differentiated under serum-free conditions for 28 days per manufacturer's instructions. The four cell lines used in this study (Lot \#: 3042901.2, 4031101.3, 2082801.2, 2120301.2) were isolated from two Caucasian male and two Caucasian female subjects, aged 54,62, 61, 56, respectively (See cell lines A, B, $\mathrm{D}, \mathrm{E}$ in Table 2). Although these cell lines were originally derived from the heart and have many cardiomyocyte properties, they are non-excitable or contractile; hence, we refer to them as cardiomyocyte-like throughout the dataset. Briefly, cells were subcultured at $37^{\circ} \mathrm{C}$ under $5 \%$ $\mathrm{CO}_{2}$ with the manufacturer-supplied and serum-supplemented growth media (Cat \#: C22270, C39275) up until passage four. Once they reached $100 \%$ confluence, cells were trypsinized, counted, and replated in serum-free growth media (Cat \#: C22270), at a concentration of 40,000 cells $/ \mathrm{cm}^{2}$ in $60 \mathrm{~mm}$ tissue culture dishes. Cells were then differentiated under serum-free conditions for 28 days, whereby $50 \%$ of the media was replenished every other day. All experiments were performed on sixth or earlier passage cells. After 28 days of differentiation, cells were treated with individual Kls for 48 hours at a concentration equivalent to clinicallyobserved median peak plasma concentration (see Table 1 for additional drug metadata). After 48 hours of KI treatment (see the drug treatment schedule in Table 2), cells were lysed on ice using TRIzol (Thermo Fisher, Cat \#: 15596026) for five minutes, scraped off the dish, and mixed. TRIzol lysates were mixed with chloroform according to manufacturer's instructions and the 
RNA-protein fractions were separated. From these organic partitions, RNA samples were processed, sequenced and analyzed as previously reported ${ }^{17}$.

\section{Protein extraction}

After isolating RNA, the remaining TRIzol solutions were processed for protein extractions. Each TRIzol extract were first separated into two $1.5 \mathrm{~mL}$ Eppendorf tubes; each tube contained $\sim 600 \mu \mathrm{l}$ of the TRIzol chloroform and methanol solvent mixture. Then to each tube, $900 \mu$ of pre-chilled cold acetone was added and mixed well. Five hundred $\mu \mathrm{L}$ of the mixture was transferred from each tube to a third new tube, and $500 \mu \mathrm{L}$ pre-chilled $-20^{\circ} \mathrm{C}$ acetone was added to each of the three tubes and mixed well. All three tubes were put on ice for at least 12 hours inside a cold room, and centrifuged at 16,000 rpm ( 23,469 g) for $30 \mathrm{~min}$, in a Beckman Coulter Allegra 64R centrifuge. After centrifugation, the supernatants were removed and $1 \mathrm{~mL}$ of pre-chilled acetone were added to each tube to wash the protein pellets. The protein pellets were sonicated for five bursts at level-3, repeated once. The protein solutions were placed on ice for 4 hours and pelleted via centrifugation as described above. The wash procedure for each protein pellet was repeated twice for a total of three times. The final protein pellet was washed with $50 \mu \mathrm{L}$ of pre-chilled acetone and centrifuged at 16,000 rpm for $10 \mathrm{~min}$, and the remaining pellet was air dried at room temperature for 10 to 15 minutes. The protein pellet was then resolubilized with a vortex mixer, with $70 \mu \mathrm{l}$ of $8 \mathrm{M}$ urea (Fisher Cat \#: U15500) in $50 \mathrm{mM}$ ammonium bicarbonate (Sigma Cat\#: 09830-500G), and stored at $-80^{\circ} \mathrm{C}$ before proteomics analysis. See additional protocol details at https://martip03.u.hpc.mssm.edu/sop.php.

\section{Sample preparation for proteomics analysis (Fig. 2):}


The protein solutions may contain TRIzol and other low mass contaminants from the RNA extraction buffer, which can confound accurate protein estimation via conventional biochemical assays. Consequently, we ran the SDS-PAGE gels to remove the low mass contaminants from the high mass proteins, and estimated the protein amounts via the stain intensities from the gels stained with the Coomassie brilliant blue (CBB) dyes (see examples in Supplementary Fig. 1). In each gel, a HeLa cell extract (Pierce, Cat \# 88329, $25 \mu \mathrm{g}$ ) was run as the normalization reference, along with the proteins isolated from the drug-treated cell lines. After Coomassie blue staining of the gels, the density of each sample lane was measured using the ImageJ software $(\mathrm{NIH})$, and the protein amount for each drug-treated sample was calculated using the following equation: protein $(\mu \mathrm{g})=$ HeLa protein $25 \mu \mathrm{g} \times($ Sample density $/$ HeLa density). The protein quantity information was later used to dilute the tryptic peptides into $0.5 \mu \mathrm{g}$ protein equivalent per $\mu$ for the LC-MS/MS analysis (Supplementary Table 1).

The in-gel digestions of proteins were performed following a procedure similar to the one described by the Mann lab ${ }^{18}$. In brief, the entire gel lane of each sample was excised into $\sim 1$ $\mathrm{cm}^{2}$ gel blocks, and washed four times with $10 \mathrm{~mL}$ each of a Wash Buffer containing $30 \%$ acetonitrile $(\mathrm{ACN})$ and $70 \%$ of $100 \mathrm{mM} \mathrm{NH}_{4} \mathrm{HCO}_{3}$ to remove the contaminants from the RNA extraction buffer. Subsequently, one $\mathrm{mL}$ of $25 \mathrm{mM}$ dithiothreitol (DTT) solution was added to the gel blocks for disulfide reduction at $55^{\circ} \mathrm{C}$ for $30 \mathrm{~min}$, and $1 \mathrm{~mL}$ of $50 \mathrm{mM}$ iodoacetamide solution was then added for thiol alkylation at $37^{\circ} \mathrm{C}$ in the dark for $30 \mathrm{~min}$. After alkylation, the gel blocks were dehydrated with $9 \mathrm{~mL}$ of ACN to remove both DTT and iodoacetamide. For in-gel trypsin digestion, one $\mathrm{mL}$ of trypsin solution $\left(5 \mu \mathrm{g} / \mathrm{mL}\right.$ in $\left.50 \mathrm{mM} \mathrm{NH}_{4} \mathrm{HCO}_{3}\right)$ was added into each sample, and incubated at $37^{\circ} \mathrm{C}$ for $16 \mathrm{~h}$. Resulting peptides were extracted, desalted with Pierce $\mathrm{C}_{18}$ spin columns (Thermo Scientific) based on the manufacturer's protocol and concentrated in a Speed Vac prior to LC-MS/MS analysis. 


\section{LC-MS/MS analysis}

According to the gel-based protein amount estimates described above, the peptides from each sample were resuspended in Solvent $A(2 \% A C N$ in $0.1 \%$ formic acid (FA)) at a final concentration of $0.5 \mu \mathrm{g} / \mu \mathrm{L}$ (see examples in Supplementary Table 1). Two microgram of peptides from each sample was subjected to LC-MS/MS analysis on a $Q$ Exactive Mass Spectrometer coupled with an UltiMate 3000 RSLCnano Duo LC system (Thermo Scientific). The peptides were first loaded onto a trapping column (Acclaim PepMap $100 \mathrm{C}_{18}$ trap column $75 \mu \mathrm{m} \times 2 \mathrm{~cm}, 3 \mu \mathrm{m}, 100 \AA)$ and then separated on an Acclaim PepMap $C_{18}$ column $(75 \mu \mathrm{m} \times$

$50 \mathrm{~cm}, 2 \mu \mathrm{m}, 100 \AA)$, using a 4-h binary gradient from $2-100 \%$ of Solvent B (85\% ACN in $0.1 \%$ FA), at a flow rate of $250 \mathrm{~nL} / \mathrm{min}$. The eluted peptides were directly introduced into the $\mathrm{MS}$ system for data-dependent MS/MS analysis in the positive ion mode. The MS full scans were acquired in an $\mathrm{m} / \mathrm{z}$ range of 400 to 1750 , with the $A G C$ value specified at $3 E 6$, the injection time set at $100 \mathrm{~ms}$, and in the profile mode. The resolution of the full MS scan was set to 140,000 at $\mathrm{m} / \mathrm{z} 400$. Following each full MS scan, 15 most intense ions with charge states between $2^{+}$to $5^{+}$ were selected within an isolation window of $2 \mathrm{~m} / \mathrm{z}$ for the subsequent MS/MS analysis. The AGC of MS/MS analysis was set to $5 \mathrm{E} 4$ and the dynamic exclusion was $45 \mathrm{~s}$. The peptide ions were fragmented using higher energy collision dissociation at a NCE of 27. A total 317 LC-MS/MS raw files were obtained for the proteins isolated across four different cell lines, with a total 62 different types of drug treatment conditions. Prior to running each set of drug-treated samples, a HeLa cell digest (Pierce, Cat \# 88329) was run as a reference to quality control the LC-MS/MS system.

\section{MaxQuant for protein identification and quantification:}


In order to evaluate the quality of the data and compare the quantitative proteomic signatures among the drug-treated samples across different cell lines, the entire 381 raw LCMS/MS dataset (317 samples and 64 HeLa cell controls, 825 GB of data) were submitted for database search using the Andromeda search engine on the MaxQuant platform (Version 1.6.0.13). The raw data files were loaded with "No fractions" option selected. Trypsin was selected as enzyme with two miss cleavages. Methionine oxidation (+15.9949 Da) and protein N-terminal acetylation (+42.0106 Da) were selected as various modifications and cysteine carbamidomethyl modification (+57.0215 Da) was set as a fixed modification. Initial search peptide mass tolerance was set to $20 \mathrm{ppm}$, and the main search peptide mass tolerance was set to $4.5 \mathrm{ppm}$. LFQ was selected for label-free quantification, with the minimal LFQ ratio count set at 2. The MS/MS spectra were searched against both UniProt human FASTA database (downloaded from https://www.uniprot.org/proteomes/UP000005640 with the last modification date of $10 / 22 / 2018$, containing 73,101 human protein sequences) and the MaxQuant default contaminants FASTA database (containing 245 protein sequences). Match between runs was selected for maximize the protein identification and quantitation with a match time window of 0.7 min and an alignment time window of $20 \mathrm{~min}$. The protein false discovery rate (FDR) was estimated using the decoy databases containing reversed sequences of the original proteins. Proteins identified with both protein and peptide FDRs at or less than $1 \%$ were included in the final results for the subsequent analyses.

\section{Data Records}

All the raw data described in this study have been uploaded to ProteomeXchange website (http://www.proteomexchange.org/) with the project accession PXD014791, and they are freely available for the research community. In addition, the processed higher level data is available 
through LINCS Data Portal (http://lincsportal.ccs.miami.edu/dcic-portal/). Data include metadata (Data Citation 1), raw files of LC-MS/MS analysis (Data Citation 2), protein FASTA database

(Data Citation 3), and protein identification and quantitation results from the MaxQuant (Data Citation 4).

\section{Technical Validation}

We've developed a 3-tiered quality control strategy to ensure the high throughput production of deep and reproducible DToxS proteomics datasets. This strategy has enabled us to control the qualities at the protein sample level, the LC-MS/MS instrument performance level and the overall sample processing variations.

\section{Quality validation of the protein samples for LC-MS/MS}

Due to both the cost constrains of treating the human-derived cardiomyocyte-like cells with $\mathrm{KI}$ drugs and the scientific necessity to compare proteomics data with RNAseq data from the same samples, the same drug-treated cells were used to analyze protein expression, after the RNA extraction. The challenges from this approach included occasionally uneven and poor protein yields, and imprecise protein concentration estimates with the established Bradford or BCA assays, due to the confounding components in the RNA extraction buffers. In order to rigorously compare drug effects with the given high sample-to-sample variability in experimental processing, we performed an additional SDS-PAGE in-gel quantification step with a consistent positive control sample. Seventy SDS-PAGE gels were run to increase the estimation accuracy of the proteins derived from the cells (see examples in Supplementary Fig. 1); in each gel, 25 $\mu \mathrm{g}$ of HeLa cell protein lysate was included in the first lane, as the reference for both accurate protein estimation and efficient in-gel digestion, and later for LC-MS/MS data normalization. In 
brief, the densities of the CBB for each KI-treated cells in each gel lane were recorded (see examples in Supplementary Table 2). The protein amounts from each sample were extrapolated by comparing its CBB density to that of the $25 \mu \mathrm{g}$ of the HeLa proteins; the estimated protein amounts were later used to obtain $0.5 \mu \mathrm{g} / \mu \mathrm{L}$ equivalent of the tryptic peptides from each sample for LC-MS/MS analysis (see examples in Fig. 2A). For tryptic digestion, the drug-treated samples were digested along with the HeLa cell proteins separated on the same SDS-PAGE gels, which were later used for LC-MS/MS data normalization as well.

\section{Quality validation of the LC-MS/MS system}

To ensure that LC-MS/MS system could deliver overall satisfactory performance, $200 \mathrm{ng}$ of the commercial HeLa cell digest was run prior to each gel batch of the biological samples. To confirm well-behaved LC separations, MS1 ions for select peptides ions were carefully monitored for retention time shrifts and peak widths. In order to minimize the run-to-run carryover of peptides, a duo-LC system was configurated in parallel for this study, so while one LC column was used for peptides separation and LC-MS/MS analysis, the other LC column could be washed to remove any residual peptides. For the over LC-MS/MS quality control, the system is capable of identifying $>3,800$ unique proteins and $>14,000$ unique peptides from the $200 \mathrm{ng}$ of the commercial HeLa cell digest. Indeed, monthly total ion current (TIC) analysis of the HeLa digest indicates consistent LC-MS/MS system performance for LFQ quantification (Fig. 2B). Qualitatively, the LC-MS/MS system enabled the deep proteome coverages ( 7,000 unique protein groups/cell line) of all four DToxS cell lines (Fig. 2C and Table 2). Total 381 raw LCMS/MS files, including the files for 317 drug treat-cells and $64 \mathrm{HeLa}$ cells, were submitted to the MaxQuant analysis (Table 2). In total, 7,193 protein groups were identified with the FDR of less than $1 \%$, among the 4 different cell lines, which were mapped to 5,734 genes. Given no multi- 
dimensional LC fractionation was performed, these deep proteome coverages confirm the effectiveness of the LC-MS/MS quality control procedures used for this study.

\section{Quality control of the quantitative data analysis}

To minimize the LC-MS/MS quantification noise derived from the sample preparation steps, the HeLa proteins used for the in-gel protein estimation were digested along with the drugtreated samples from the same gels. Thus, these HeLa cell protein digests were used to control for the trypsin digestion efficiencies, LC/MS/MS variations and for the quantitative normalization of the LFQ data. For example, the TIC analyses indicates sample-to-samples variations among both HeLa and control cell (no drug treatment) digests (Fig. 2D, upper and middle panel, respectively); with HeLa TIC signal normalization, the variations in the control cell digests were dramatically reduced (Fig. 2D, lower panel).

Overall, our method for protein count normalization showed remarkable reproducibility (Fig 3A), which can be assessed using Pearson correlation across two technical replicates that were analyzed on different days from two different HeLa signal normalization protocols (i.e., different SDS-PAGE gels). This was consistent for all technical replicates in this dataset (Supplementary Fig 2). We note that while depth of protein quantification was high for each replicate, overlap of detected proteins between different biological replicates was consistently high for all cardiomyocyte-like cell lines (Fig 3B), suggesting that our experimental pipeline was robust in identification of proteomic signatures. The quantification strategy was also successful in reproducible identification of subtle proteomic differences between individual cardiomyocyte cell lines PMC-A, B, D and E, which clustered consistently across most biological replicates (Fig 3B). Furthermore, we used overlap analysis, to show that most of the identified proteins were 
common to either all four cell lines $(3,784$ or $66 \%)$ or detected in at least three out of four lines $(4,499$ or $78.5 \%)$ (Fig 4).

\section{Identification of differentially expressed proteins}

The normalized spectral counts of identified proteins were processed by the edgeRbased computational pipeline to generate differentially expressed proteins (DEPs) associated with statistical significance for each drug treatment in each cell line, as described before ${ }^{17}$.

\section{Downstream analysis of differentially expressed proteins}

To analyze cell line and drug specific responses, we merged all lists of DEPs of the same cell line treated with the same drug to one new list of DEPs. For each DEP in this new list, we calculated a combined $p$-value defined as the geometric mean of the individual p-values of the different treatments and a combined $\log _{2}$ (fold changes) defined as the average mean of the individual $\log _{2}$ (fold changes). For all downstream analyses, we considered the top 100 DEPS (based on the combined p-values). Combined drug treatments of the different cell lines were hierarchically clustered based on the combined $\log _{2}$ (fold changes) using Cluster $3.0{ }^{19,20}$. Finally, to investigate the consistency between the different experiments for the same drug treatment across the four cell lines, we ran successive Pearson correlations between different replicates for a given drug treatment of the same cell compared to the correlation among different cell types (Fig 5A). 
bioRxiv preprint doi: https://doi.org/10.1101/2020.02.26.966606; this version posted February 26, 2020. The copyright holder for this preprint (which was not certified by peer review) is the author/funder, who has granted bioRxiv a license to display the preprint in perpetuity. It is made available under aCC-BY-NC-ND 4.0 International license. 


\section{Usage Notes}

\section{Use case 1: Identification of KI drug-induced protein expression profiles}

This DToxS dataset can be mined to identify protein expression changes triggered by each $\mathrm{KI}$ drug treatment of the four cardiac cell lines derived from human tissues. The proteomic changes identified in this study can be used to understand the cell signal transduction events that may underlie Kl-induced cardiotoxicities. Also, with the LC-MS/MS information provided in this dataset, follow-up proteomics assays can be developed to validate the protein expression changes in larger number of samples; such assays may include either targeted assays, e.g., selected or parallel reaction monitoring (SRM or PRM) or untargeted proteomics assays, e.g., data-independent analysis (DIA).

\section{Use case 2: Comparison of differential KI drug-induced protein expression profiles}

This dataset can be analyzed to compare and cluster the proteomic changes induced by different KIs, thus ascertaining the similarities and idiosyncrasies of different drugs and patient (or cell line) specific responses (Supplementary Fig 3). One can also quantify the variability and consistency of drug-induced proteomic changes within a given subject (i.e., within a given cell line) compared across a population (i.e., between lines) to determine the generalizability of a given drug effect on cardiomyocytes (Fig 5B).

\section{Use case 3: Integration of transcript and protein expression profiles for comprehensive network studies}

Drugs may induce complex changes on either gene or protein expression. Since proteomics and RNAseq changes in complex human cells are not always in agreement, perhaps due to either technical bias, differential regulation or turnover rates; therefore, it may be desirable to 
integrate both gene and protein expression datasets, in order to obtain more comprehensive understanding of the drug-induced changes among the signaling networks. For example, the DToxS proteomics dataset presented here can be integrated with the DToxS transcriptomics dataset (www.dtoxs.org) to fully understand the effects of Kl-induced cardiotoxicities.

\section{Use case 4: Identification of drug-induced post-translational modifications (PTMs) and regulated proteolysis}

Drugs may induce changes among signaling pathways not only via the changes of gene and protein expressions, but also via the rapid regulations of protein functions by altering specific PTMs (e.g., phosphorylation) and regulated proteolytic events (e.g. caspase 3 activation) ${ }^{24-26}$. Therefore, alternative protein database search schemes can be carried out to analyze the raw DToxS proteomics dataset, and identify KI-induced changes among specific PTMs or semitryptic or non-tryptic peptides derived from regulated proteolysis (Supplementary Fig. 4). Since the current workflow did not include the enrichments of the subproteomes specific for PTMs, the yield for peptides containing PTMs or non-tryptic cleavages will likely be modest. As such, the results from the alternative analysis of the DToxS dataset may provide information for future proteomics studies that focus on the enrichments of specific PTMs, e.g. acetylation and phosphorylation. 


\section{References:}

1 Gross, S., Rahal, R., Stransky, N., Lengauer, C. \& Hoeflich, K. P. Targeting cancer with kinase inhibitors. The Journal of clinical investigation 125, 1780-1789, (2015).

2 Calizo, R. C., Bhattacharya, S. et al. Disruption of podocyte cytoskeletal biomechanics by dasatinib leads to nephrotoxicity. Nat Commun 10, 2061, (2019).

3 Sharma, A., Burridge, P. W. et al. High-throughput screening of tyrosine kinase inhibitor cardiotoxicity with human induced pluripotent stem cells. Science translational medicine 9, (2017).

4 Keenan, A. B., Jenkins, S. L. et al. The Library of Integrated Network-Based Cellular Signatures NIH Program: System-Level Cataloging of Human Cells Response to Perturbations. Cell Syst, (2017).

5 Schwanhausser, B., Busse, D. et al. Global quantification of mammalian gene expression control. Nature 473, 337-342, (2011).

6 Cancer Genome Atlas Research, N. Comprehensive molecular characterization of urothelial bladder carcinoma. Nature 507, 315-322, (2014).

7 Azeloglu, E. U., Hardy, S. V. et al. Interconnected network motifs control podocyte morphology and kidney function. Science signaling 7, ra12, (2014).

8 Trinh, H. V., Grossmann, J. et al. iTRAQ-Based and Label-Free Proteomics Approaches for Studies of Human Adenovirus Infections. Int J Proteomics 2013, 581862, (2013).

9 Johnson, E. C. B., Dammer, E. B. et al. Deep proteomic network analysis of Alzheimer's disease brain reveals alterations in RNA binding proteins and RNA splicing associated with disease. Mol Neurodegener 13, 52, (2018).

10 Beer, L. A., Liu, P., Ky, B., Barnhart, K. T. \& Speicher, D. W. Efficient Quantitative Comparisons of Plasma Proteomes Using Label-Free Analysis with MaxQuant. Methods Mol Biol 1619, 339-352, (2017).

11 Cox, J., Hein, M. Y. et al. Accurate proteome-wide label-free quantification by delayed normalization and maximal peptide ratio extraction, termed MaxLFQ. Mol Cell Proteomics 13, 2513-2526, (2014).

12 Anand, S., Samuel, M., Ang, C. S., Keerthikumar, S. \& Mathivanan, S. Label-Based and Label-Free Strategies for Protein Quantitation. Methods Mol Biol 1549, 31-43, (2017).

13 Megger, D. A., Pott, L. L. et al. Comparison of label-free and label-based strategies for proteome analysis of hepatoma cell lines. Biochim Biophys Acta 1844, 967-976, (2014).

14 Patel, V. J., Thalassinos, K. et al. A comparison of labeling and label-free mass spectrometry-based proteomics approaches. J Proteome Res 8, 3752-3759, (2009).

15 Bantscheff, M., Schirle, M., Sweetman, G., Rick, J. \& Kuster, B. Quantitative mass spectrometry in proteomics: a critical review. Anal Bioanal Chem 389, 1017-1031, (2007).

16 Bantscheff, M., Lemeer, S., Savitski, M. M. \& Kuster, B. Quantitative mass spectrometry in proteomics: critical review update from 2007 to the present. Anal Bioanal Chem 404, 939-965, (2012).

17 Xiong, Y., Soumillon, M. et al. A Comparison of mRNA Sequencing with Random Primed and 3'-Directed Libraries. Sci Rep 7, 14626, (2017).

18 Shevchenko, A., Tomas, H., Havlis, J., Olsen, J. V. \& Mann, M. In-gel digestion for mass spectrometric characterization of proteins and proteomes. Nat Protoc 1, 2856-2860, (2006).

19 Eisen, M. B., Spellman, P. T., Brown, P. O. \& Botstein, D. Cluster analysis and display of genome-wide expression patterns. Proc Natl Acad Sci U S A 95, 14863-14868, (1998). 
20 de Hoon, M. J., Imoto, S., Nolan, J. \& Miyano, S. Open source clustering software. Bioinformatics 20, 1453-1454, (2004).

21 Hansen, J., Meretzky, D., Woldesenbet, S., Stolovitzky, G. \& lyengar, R. A flexible ontology for inference of emergent whole cell function from relationships between subcellular processes. Sci Rep 7, 17689, (2017).

22 Karakikes, I., Senyei, G. D. et al. Small molecule-mediated directed differentiation of human embryonic stem cells toward ventricular cardiomyocytes. Stem cells translational medicine 3, 18-31, (2014).

23 van Hasselt, J. G. C., Hansen, J. et al. Clinically-weighted transcriptomic signatures for protein kinase inhibitor associated cardiotoxicity. bioRxiv, (2016).

24 Liu, T., Donahue, K. C. et al. Identification of differentially expressed proteins in experimental autoimmune encephalomyelitis (EAE) by proteomic analysis of the spinal cord. J Proteome Res 6, 2565-2575, (2007).

25 Grant, J. E., Hu, J. et al. Post-translational modifications in the rat lumbar spinal cord in experimental autoimmune encephalomyelitis. J Proteome Res 6, 2786-2791, (2007).

26 Jain, M. R., Li, Q. et al. Proteomic identification of immunoproteasome accumulation in formalin-fixed rodent spinal cords with experimental autoimmune encephalomyelitis. J Proteome Res 11, 1791-1803, (2012).

27 Schnell, D., Buschke, S. et al. Pharmacokinetics of afatinib in subjects with mild or moderate hepatic impairment. Cancer Chemother Pharmacol 74, 267-275, (2014).

28 Stopfer, P., Marzin, K. et al. Afatinib pharmacokinetics and metabolism after oral administration to healthy male volunteers. Cancer Chemother Pharmacol 69, 1051-1061, (2012).

29 Pithavala, Y. K., Chen, Y. et al. Evaluation of the effect of food on the pharmacokinetics of axitinib in healthy volunteers. Cancer Chemother Pharmacol 70, 103-112, (2012).

30 Rugo, H. S., Herbst, R. S. et al. Phase I trial of the oral antiangiogenesis agent AG013736 in patients with advanced solid tumors: pharmacokinetic and clinical results. $J$ Clin Oncol 23, 5474-5483, (2005).

31 Abbas, R., Hug, B. A. et al. A phase I ascending single-dose study of the safety, tolerability, and pharmacokinetics of bosutinib (SKI-606) in healthy adult subjects. Cancer Chemother Pharmacol 69, 221-227, (2012).

32 Kurzrock, R., Sherman, S. I. et al. Activity of XL184 (Cabozantinib), an oral tyrosine kinase inhibitor, in patients with medullary thyroid cancer. J Clin Oncol 29, 2660-2666, (2011).

33 Ouellet, D., Gibiansky, E. et al. Population pharmacokinetics of dabrafenib, a BRAF inhibitor: effect of dose, time, covariates, and relationship with its metabolites. $J$ Clin Pharmacol 54, 696-706, (2014).

34 Falchook, G. S., Long, G. V. et al. Dabrafenib in patients with melanoma, untreated brain metastases, and other solid tumours: a phase 1 dose-escalation trial. Lancet 379, 18931901, (2012).

35 McCaig, A. M., Cosimo, E., Leach, M. T. \& Michie, A. M. Dasatinib inhibits CXCR4 signaling in chronic lymphocytic leukaemia cells and impairs migration towards CXCL12. PloS one 7, e48929, (2012).

36 Herbst, R. S., Prager, D. et al. TRIBUTE: a phase III trial of erlotinib hydrochloride (OSI774) combined with carboplatin and paclitaxel chemotherapy in advanced non-small-cell lung cancer. J Clin Oncol 23, 5892-5899, (2005).

37 Soulieres, D., Senzer, N. N. et al. Multicenter phase II study of erlotinib, an oral epidermal growth factor receptor tyrosine kinase inhibitor, in patients with recurrent or metastatic squamous cell cancer of the head and neck. J Clin Oncol 22, 77-85, (2004). 
38 Hirano, S., Sano, K. et al. The pharmacokinetics and long-term therapeutic effects of gefitinib in patients with lung adenocarcinoma harboring the epidermal growth factor receptor(EGFR)mutation. Gan To Kagaku Ryoho 39, 1501-1506, (2012).

39 Demetri, G. D., Wang, Y. et al. Imatinib plasma levels are correlated with clinical benefit in patients with unresectable/metastatic gastrointestinal stromal tumors. J Clin Oncol 27, 3141-3147, (2009).

40 LoRusso, P. M., Jones, S. F. et al. Phase I and pharmacokinetic study of lapatinib and docetaxel in patients with advanced cancer. J Clin Oncol 26, 3051-3056, (2008).

41 Trent, J. \& Molimard, M. Pharmacokinetics and pharmacodynamics of nilotinib in gastrointestinal stromal tumors. Semin Oncol 38 Suppl 1, S28-33, (2011).

42 Tanaka, C., Yin, O. Q. et al. Clinical pharmacokinetics of the BCR-ABL tyrosine kinase inhibitor nilotinib. Clin Pharmacol Ther 87, 197-203, (2010).

43 Hurwitz, H. I., Dowlati, A. et al. Phase I trial of pazopanib in patients with advanced cancer. Clin Cancer Res 15, 4220-4227, (2009).

44 Narasimhan, N. I., Dorer, D. J., Niland, K., Haluska, F. \& Sonnichsen, D. Effects of ketoconazole on the pharmacokinetics of ponatinib in healthy subjects. $J$ Clin Pharmacol 53, 974-981, (2013).

45 Rey, J. B., Launay-Vacher, V. \& Tournigand, C. Regorafenib as a single-agent in the treatment of patients with gastrointestinal tumors: an overview for pharmacists. Target Oncol 10, 199-213, (2015).

46 Shi, J. G., Chen, X. et al. The pharmacokinetics, pharmacodynamics, and safety of orally dosed INCB018424 phosphate in healthy volunteers. J Clin Pharmacol 51, 1644-1654, (2011).

47 Chen, X., Shi, J. G. et al. Pharmacokinetics and pharmacodynamics of orally administered ruxolitinib (INCB018424 phosphate) in renal and hepatic impairment patients. Clin Pharmacol Drug Dev 3, 34-42, (2014).

48 Minkin, P., Zhao, M. et al. Quantification of sunitinib in human plasma by highperformance liquid chromatography-tandem mass spectrometry. J Chromatogr B Analyt Technol Biomed Life Sci 874, 84-88, (2008).

49 Faivre, S., Delbaldo, C. et al. Safety, pharmacokinetic, and antitumor activity of SU11248, a novel oral multitarget tyrosine kinase inhibitor, in patients with cancer. J Clin Oncol 24, 25-35, (2006).

50 Kim, K. B., Kefford, R. et al. Phase II study of the MEK1/MEK2 inhibitor Trametinib in patients with metastatic BRAF-mutant cutaneous melanoma previously treated with or without a BRAF inhibitor. J Clin Oncol 31, 482-489, (2013).

51 Martin, P., Oliver, S. et al. Pharmacokinetic drug interactions with vandetanib during coadministration with rifampicin or itraconazole. Drugs $R D$ 11, 37-51, (2011).

52 Grippo, J. F., Zhang, W. et al. A phase I, randomized, open-label study of the multipledose pharmacokinetics of vemurafenib in patients with BRAF V600E mutation-positive metastatic melanoma. Cancer Chemother Pharmacol 73, 103-111, (2014). 


\section{Data Citations}

1. Xiong et. al (Web link) (2019) (Meta data)

2. Xiong et. al (Web link) (2019) (Raw data)

3. Xiong et. al (Web link) (2019) (Fasta)

4. Xiong et. al (Web link) (2019) (MaxQuant Tables)

\section{Acknowledgements}

The authors are grateful for the support from the NIH Common Fund's Library of Integrated Cellular Signatures (LINCS) grant U54 HG008098 to R.I., M.R.B., E.A.S. In addition, R.I. is supported in part by NIH GM072853; H.L. is supported in part by NIH R01 GM112415; and E.U.A. is supported in part by NIH R01 DK118222. Mass spectrometer purchases were supported by NIH grant P30 NS046593 from the National Institute of Neurological Disorders and Stroke and another NIH grant 1S10 OD025047 from the Office of the Director of the National Institutes of Health. S.S. and D.V. are supported by NIH U54 HL127624. The content is sole responsibility of the authors and does not necessarily represent the official views of the National Institutes of Health.

\section{Author Contributions}

R.I., E.U.A. and H.L. conceived the project. Y.X. developed the analytical pipeline for proteomic and transcriptomic data processing and tabulated all data and metadata. T.L. executed the LCMS/MS workflow and data analysis. T.C. performed protein SDS-PAGE analysis and in-gel tryptic digestions. B.H., Y.C., G.J. performed cell culture experiments along with protein and RNA isolation. J.H. developed the bioinformatic pipeline for integrative analysis. S.S., D.V. and J.G. assisted in the development and organization of quality control and metadata standards. 
H.L. designed the proteomics sample preparation and proteomics analysis workflow from expert input from M.R.B., E.A.S., R.I., and E.U.A. The manuscript was written by H.L., T.L. and E.U.A. with critical input from all the authors. E.U.A. provided overall supervision for all phases of the project.

\section{Additional Information}

Supplemental Information accompanies this paper at http://www.nature.com/sdata

Competing Interests

The authors declare no competing financial interests. 
Figures and Tables

Figure 1. LFQ proteomics workflow for the DToxS Study

Figure 2. Quality control for the DToxS Study

Figure 3. Reproducibility of protein expression measurements for control samples

Figure 4. Coverage of identified proteins across cell lines

Figure 5. Reproducibility of protein expression measurements for drug-treated samples

Table 1. Drug metadata

Table 2. Cellular metadata

Table 3. Summary of MaxQuant analytics 


\section{A}

Kinase Inhibitor

[Clinically-derived peak

plasma concentration]

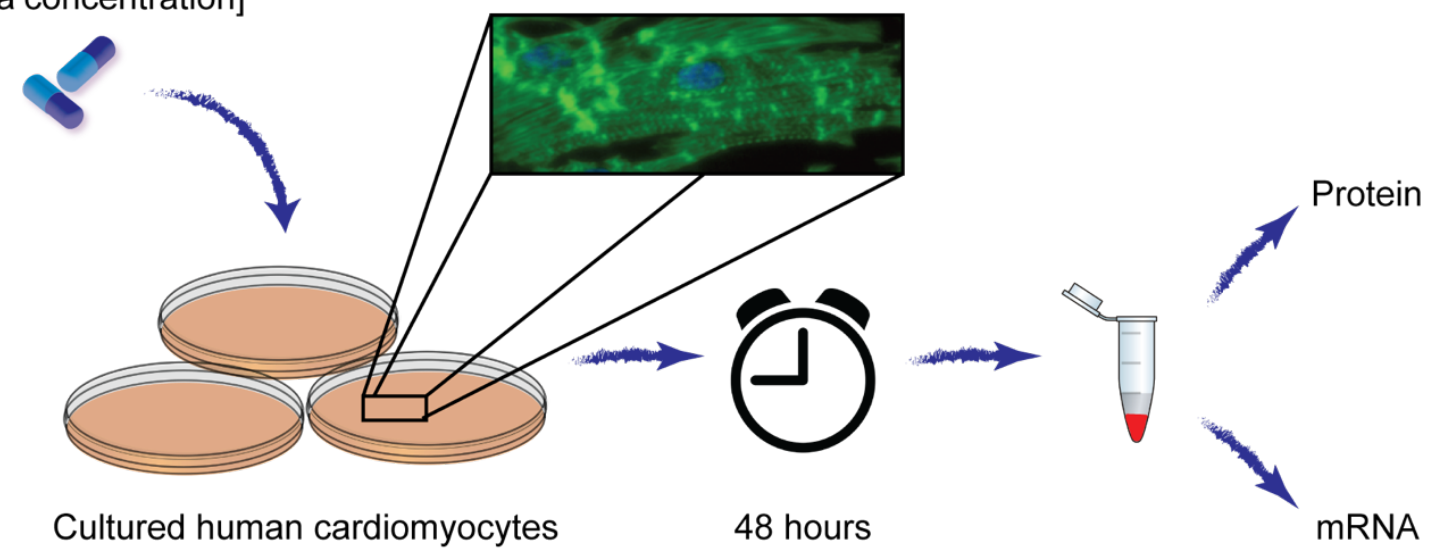

\section{B}

Cultured human cardiomyocytes

48 hours

mRNA

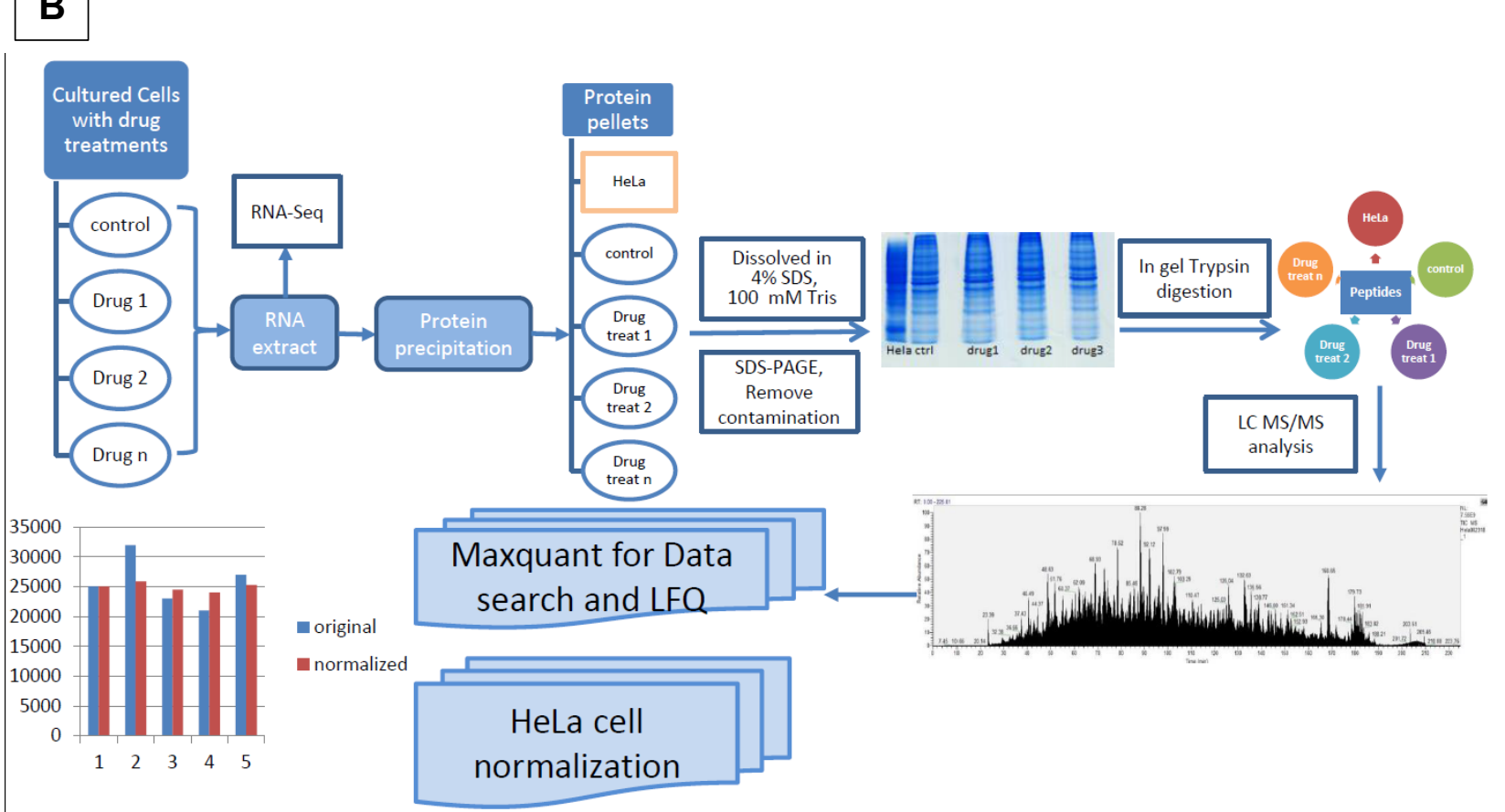

Figure 1. LFQ proteomics workflow for the DToxS Study. (A) Drug and cell treatment design and experimental workflow. (B) After drug treatment, RNA were isolated from the cells, and the remaining proteins were recovered via protein precipitation. The protein amounts were carefully estimated from their SDS-PAGE staining intensities as measured relative to a HeLa cell lysate standard. Two $\mu$ g of protein from each sample were analyzed by LC-MS/MS, and the resulting proteins were quantified by a LFQ approach using MaxQuant. 
bioRxiv preprint doi: https://doi.org/10.1101/2020.02.26.966606; this version posted February 26, 2020. The copyright holder for this preprint (which was not certified by peer review) is the author/funder, who has granted bioRxiv a license to display the preprint in perpetuity. It is made available under aCC-BY-NC-ND 4.0 International license.

A

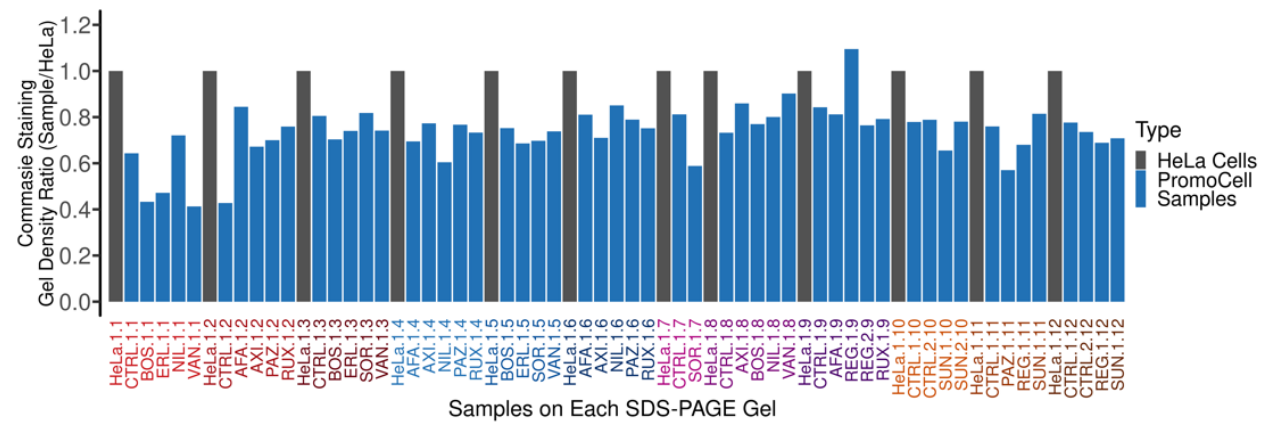

B

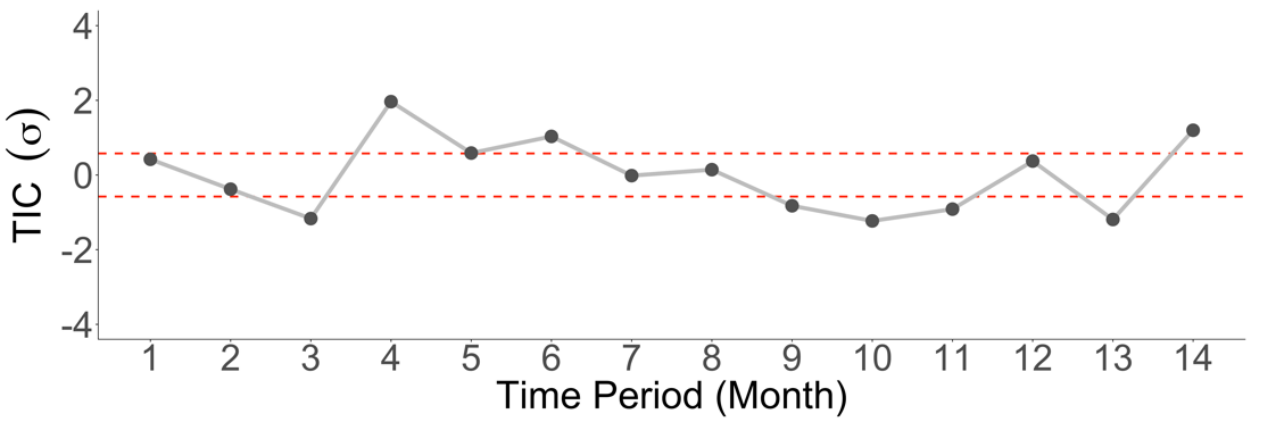

C
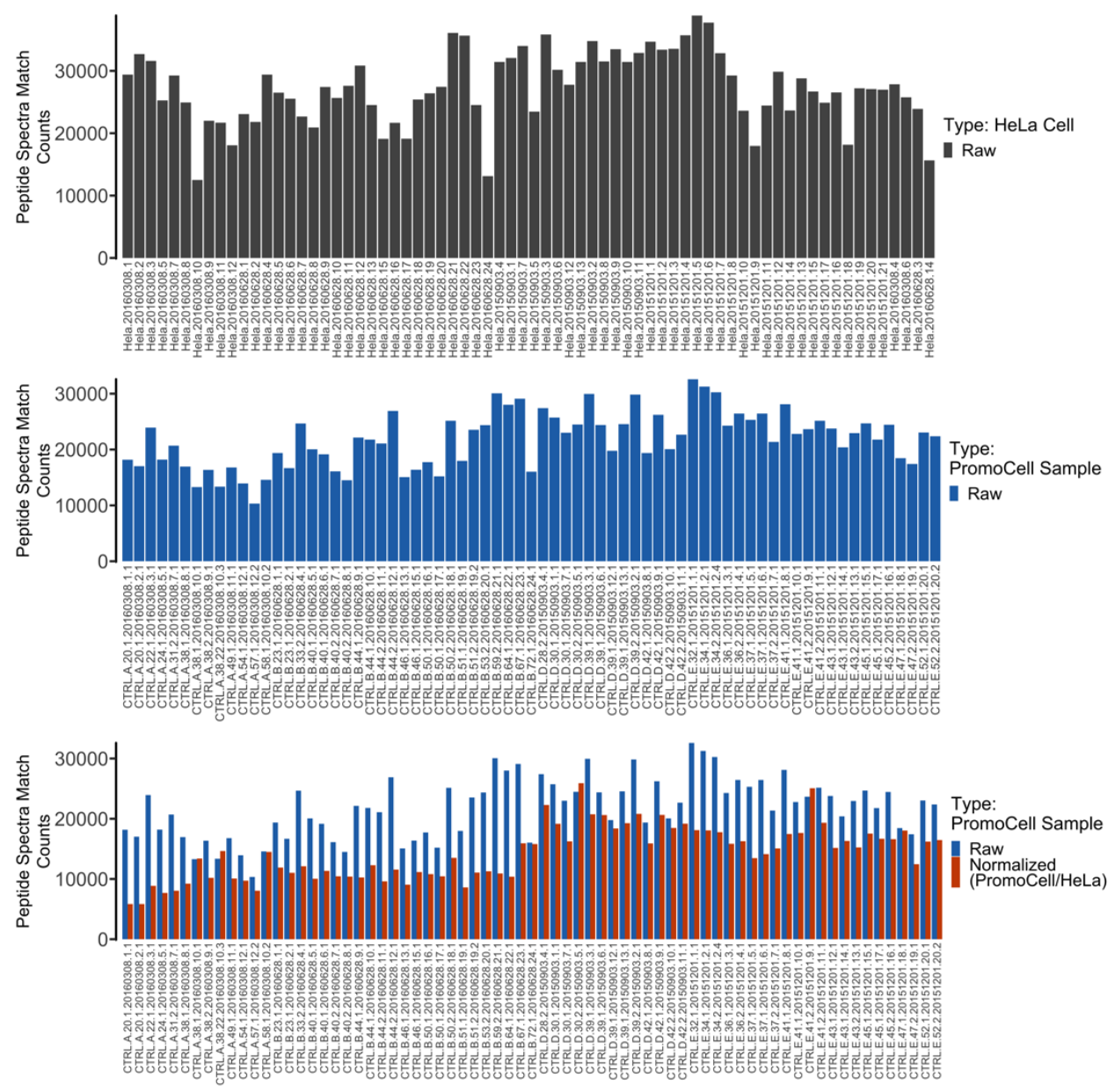
Figure 2. MS/MS quality control for the DToxS Study. A series of quality control steps have been implemented to obtain high quality data for this study. (A) A gel-based method developed for protein estimation. In each SDS-PAGE gel, $25 \mu \mathrm{g}$ of HeLa cell protein extract was run as a reference to estimate the total protein amount of each sample (blue verticle lines). Based on the density of the CBB stain of each lane in relation to the HeLa stain density, the protein amount can be calculated (see examples in Supplementary Table 1). After the tryptic digestions, the resulting peptides were diluted into $0.5 \mu \mathrm{g} / \mathrm{ml}$ for LC-MS/MS analysis (orange verticle lines), based on the estimated protein amount in each sample. (B) A commercial HeLa digest used for LC-MS/MS quality control. Two hundred ng of HeLa protein digest was analyzed regulary to ensure good LC-MS/MS instrument performance. During the time period of the DToxS LINCS data acquisition, the total ion current (TIC) of a representative HeLa cell digestion from each month is plotted monthly, indicating consistent LC-MS signal response from the commercial HeLa digest. (C) Deep proteome coverage indicates good instrument sensitivity. The total protein groups identified from each cell line in this study are shown, with $\sim 7,000$ proteins identified per cell line. (D) The HeLa protein digest from (A) were used LFQ normalization. Based on the MS1 LFQ counts of the HeLa cells from each gel (top panel), a normalization factor was calculated and applied to the MS1 counts of the samples (the control cell data before normalization is shown in the middle panel). After the HeLa cell normalization, the LFQ variation was dramatically reduced (lower panel). 
A

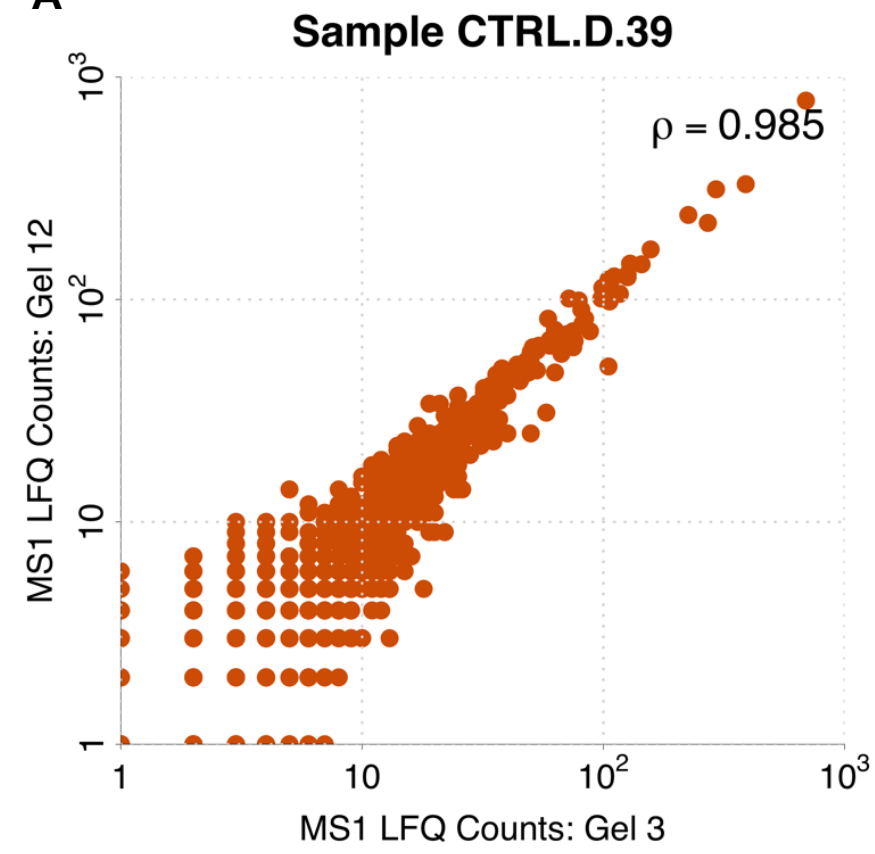

C

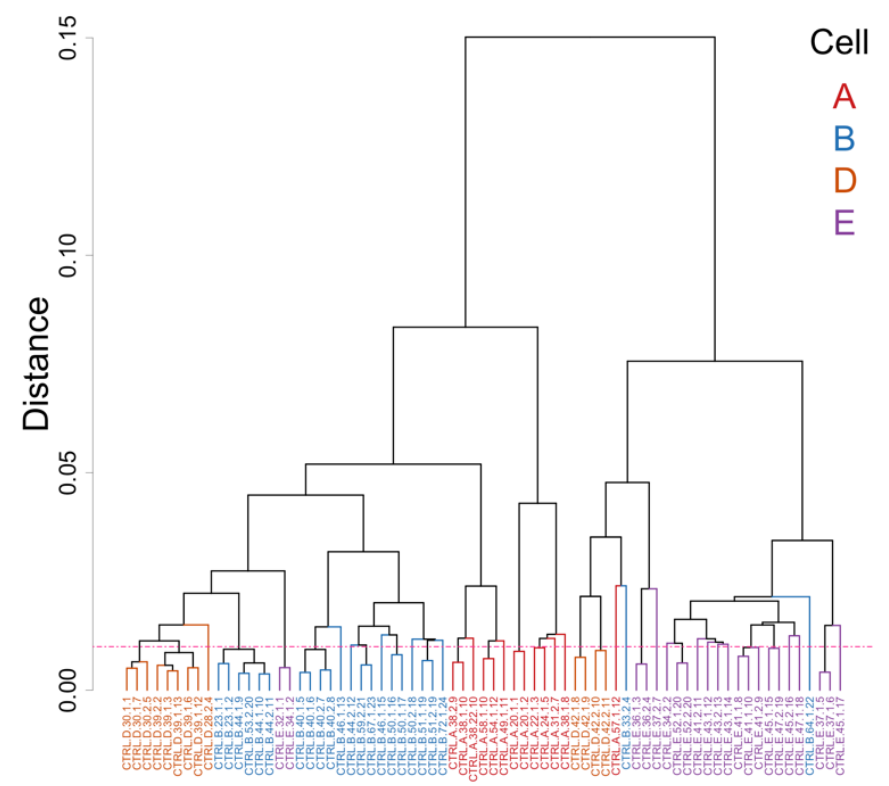

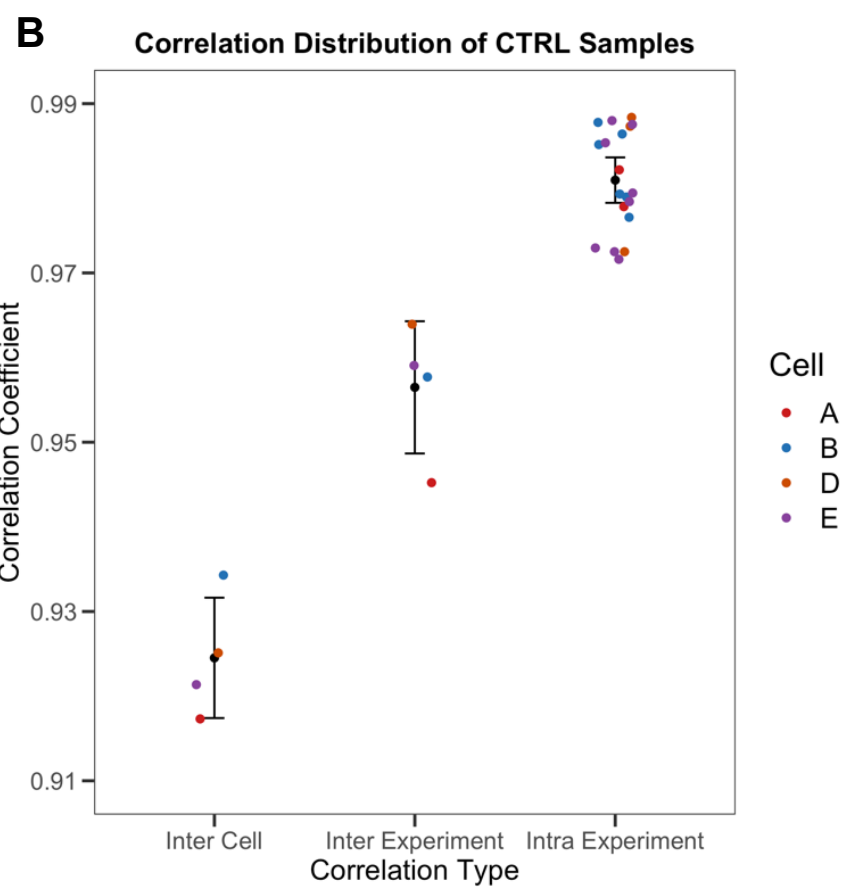

D

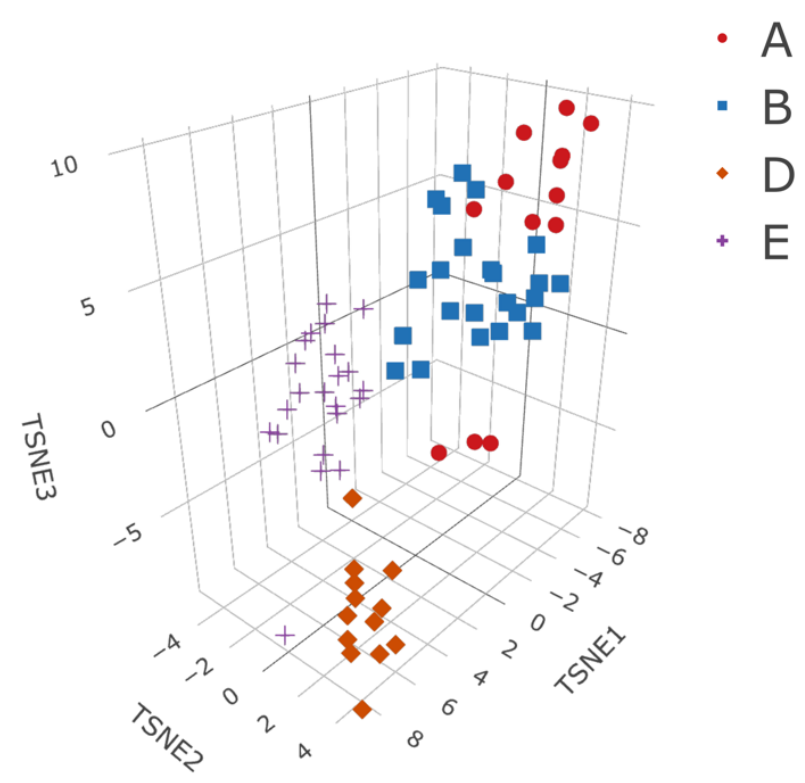

Figure 3. Reproducibility of detected proteins in control samples. (A) Normalized MS1 LFQ counts for the same sample measured from two separate SDS-PAGE gels in two different MS/MS runs had strong agreement. (B) The correlation (mean and variation) of spectral counts between the control samples from the same experiment for each experiment versus the samples from different experiments in each cell line (cell lines A, B, D, E shown in color coordination). (C) The clustering of all biological replicates from four cell lines under control conditions based on the Eucledian distances of spectral counts of replicate samples. (D) Accordingly, proteomic signatures of the four cell lines under control conditions across 71 biological replicates showed strong clustering based on the source cell line. 


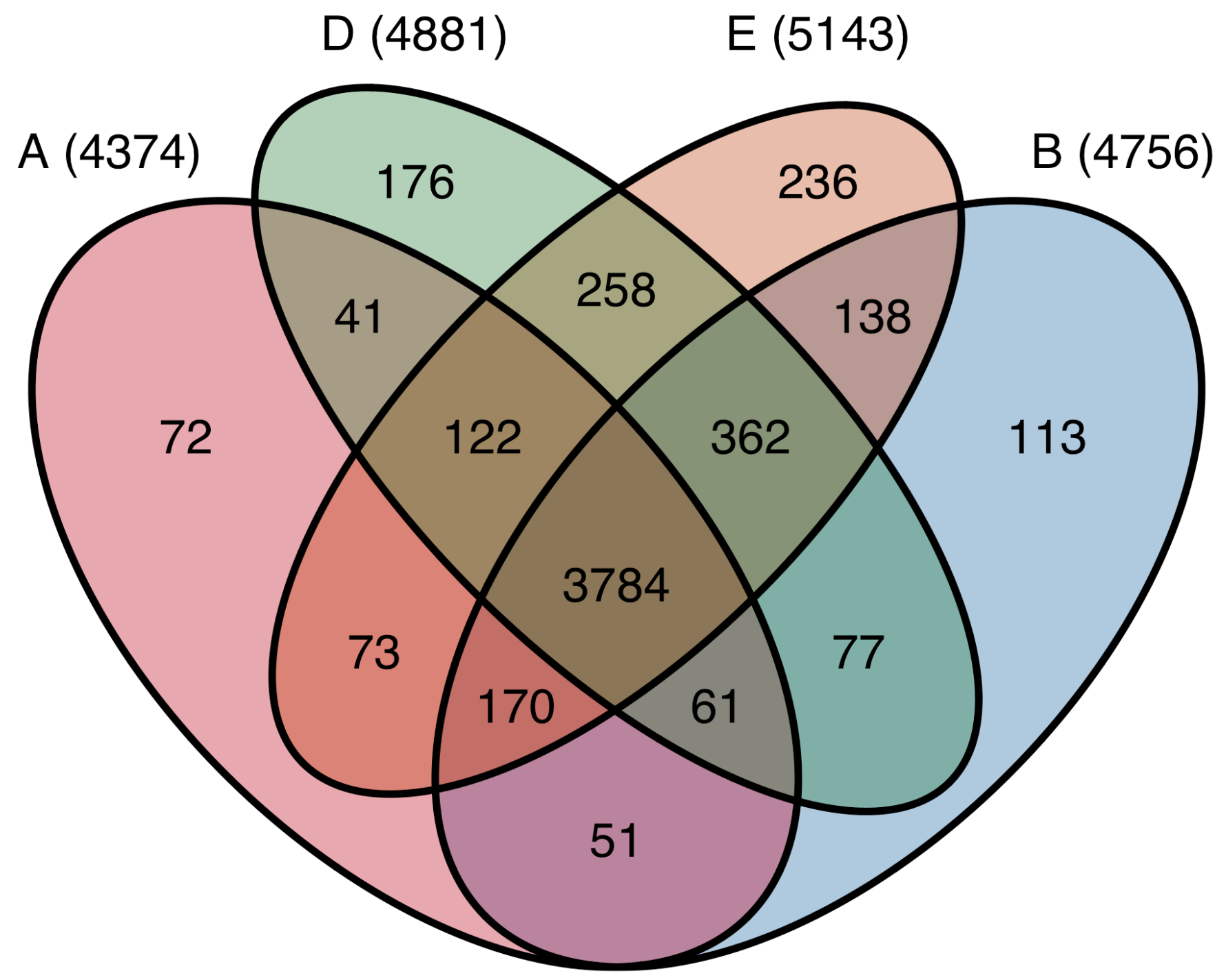

Figure 4. Coverage of identified proteins across cell lines. Venn diagram of the overlapping and unique proteins across all samples for the four PromoCell cardiomyocyte lines (A, B, D, E). 
A

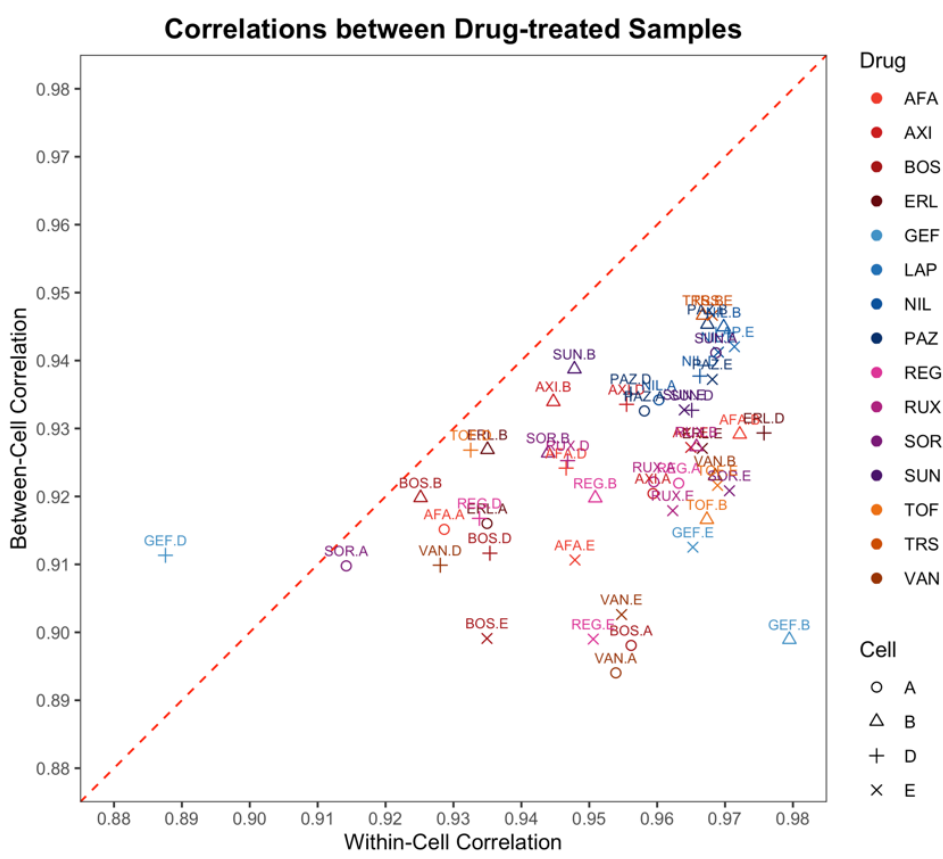

B

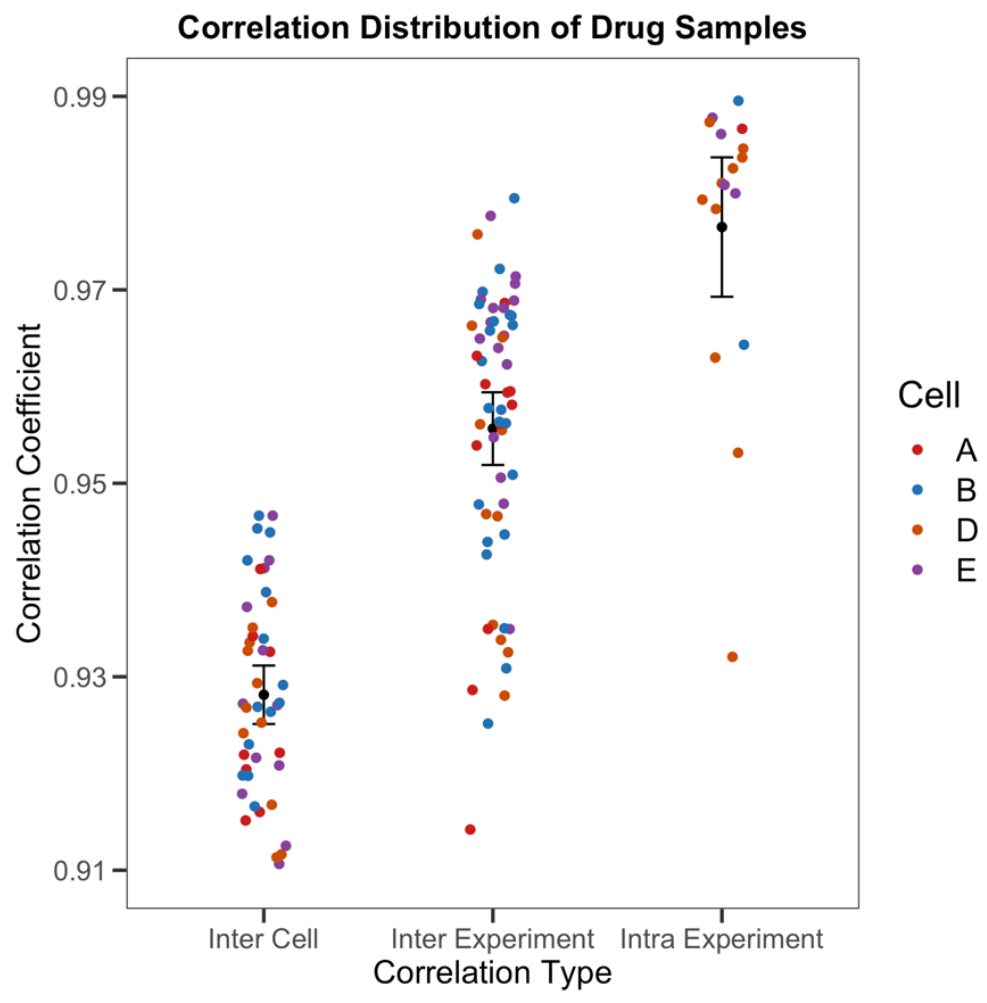

Figure 5. Reproducibility of protein expression measurements for drug-treated samples. (A) The similarity and variability of drug-treated samples within and between cell lines as determined by Pearson correlation between drug treated replicates and controls. (B) A summary of the drugs showing similar profiles between cells versus those showing different profiles within cells. 
Table 1. Drug metadata. Purity was verified for each lot number. The concentration used for each drug is equivalent to the clinically-observed median peak plasma concentration as per the cited reference.

\begin{tabular}{|c|c|c|c|c|c|}
\hline Drug & Acronym & Drug Form & Purity & Concentration $(\boldsymbol{\mu M})$ & Reference \\
\hline Afatinib & AFA & & 98.8 & 0.05 & 27,28 \\
\hline Axitinib & AXI & & 98.0 & 0.2 & 29,30 \\
\hline Bosutinib & BOS & & 98.0 & 0.1 & 31 \\
\hline Cabozantinib & CAB & & 99.1 & 2 & 32 \\
\hline Dabrafenib & DAB & & 99.61 & 2.5 & 35 \\
\hline Dasatinib & DAS & & 98.36 & 0.1 & 36,37 \\
\hline Erlotinib & ERL & & 99.32 & 3 & 38 \\
\hline Gefitinib & GEF & & 99.25 & 1 & 39 \\
\hline Imatinib & IMA & & 99.48 & 5 & 40 \\
\hline Lapatinib & LAP & & 99.0 & 2 & 41,42 \\
\hline Nilotinib & NIL & & 99.77 & 3 & 43 \\
\hline Pazopanib & PAZ & & 96.13 & 10 & 44 \\
\hline Ponatinib & PON & & 97.29 & 0.1 & 45 \\
\hline Regorafenib & REG & & 99.58 & 1 & 46,47 \\
\hline Ruxolitinib & RUX & & 99.38 & 1 & 46,47 \\
\hline Sorafenib & SOR & Tosylate & 99.73 & 0.5 & 48,49 \\
\hline Sunitinib & SUN & Malate & 97.13 & 1 & 50 \\
\hline Trametinib & TRA & & 99.24 & 0.1 & 50 \\
\hline Tofacitinib & TOF & Citrate & 99.85 & 1 & 51 \\
\hline Vandetanib & VAN & & 99.73 & 0.333 & 52 \\
\hline Vemurafenib & VEM & & 98.08 & 2 & \\
\hline
\end{tabular}


bioRxiv preprint doi: https://doi.org/10.1101/2020.02.26.966606; this version posted February 26, 2020. The copyright holder for this preprint (which was not certified by peer review) is the author/funder, who has granted bioRxiv a license to display the preprint in perpetuity. It is made available under aCC-BY-NC-ND 4.0 International license.

\section{Table 2. Cellular metadata}

\begin{tabular}{|c|c|c|c|c|c|c|c|}
\hline Cell Name & Vendor & Cat No & Lot No & Race & Sex & Age & Disease \\
\hline PMC-A & PromoCell & C-12810 & 3042901.2 & Caucasian & Male & 54 & None \\
\hline PMC-B & PromoCell & C-12810 & 4031101.3 & Caucasian & Female & 62 & None \\
\hline PMC-D & PromoCell & C-12810 & 2082801.2 & Caucasian & Female & 61 & None \\
\hline PMC-E & PromoCell & C-12810 & 2120301.2 & Caucasian & Male & 56 & None \\
\hline
\end{tabular}


Table 3. Summary of MaxQuant analytics

\begin{tabular}{|c|c|c|c|c|}
\hline Group & PMC-A & PMC-B & PMC-D & PMC-E \\
\hline Total Identified Protein Groups & 6,803 & 6,968 & 6,945 & 7,021 \\
\hline Total Identified Peptides & $1,599,186$ & $3,266,823$ & $2,023,891$ & $3,227,847$ \\
\hline Total Unique Peptides & $1,090,438$ & $2,224,679$ & $1,423,505$ & $2,252,728$ \\
\hline Median LFQ Intensity & $14,430,000$ & $15,755,000$ & $13,306,000$ & $12,503,000$ \\
\hline
\end{tabular}




\section{Supplementary Figures and Tables}

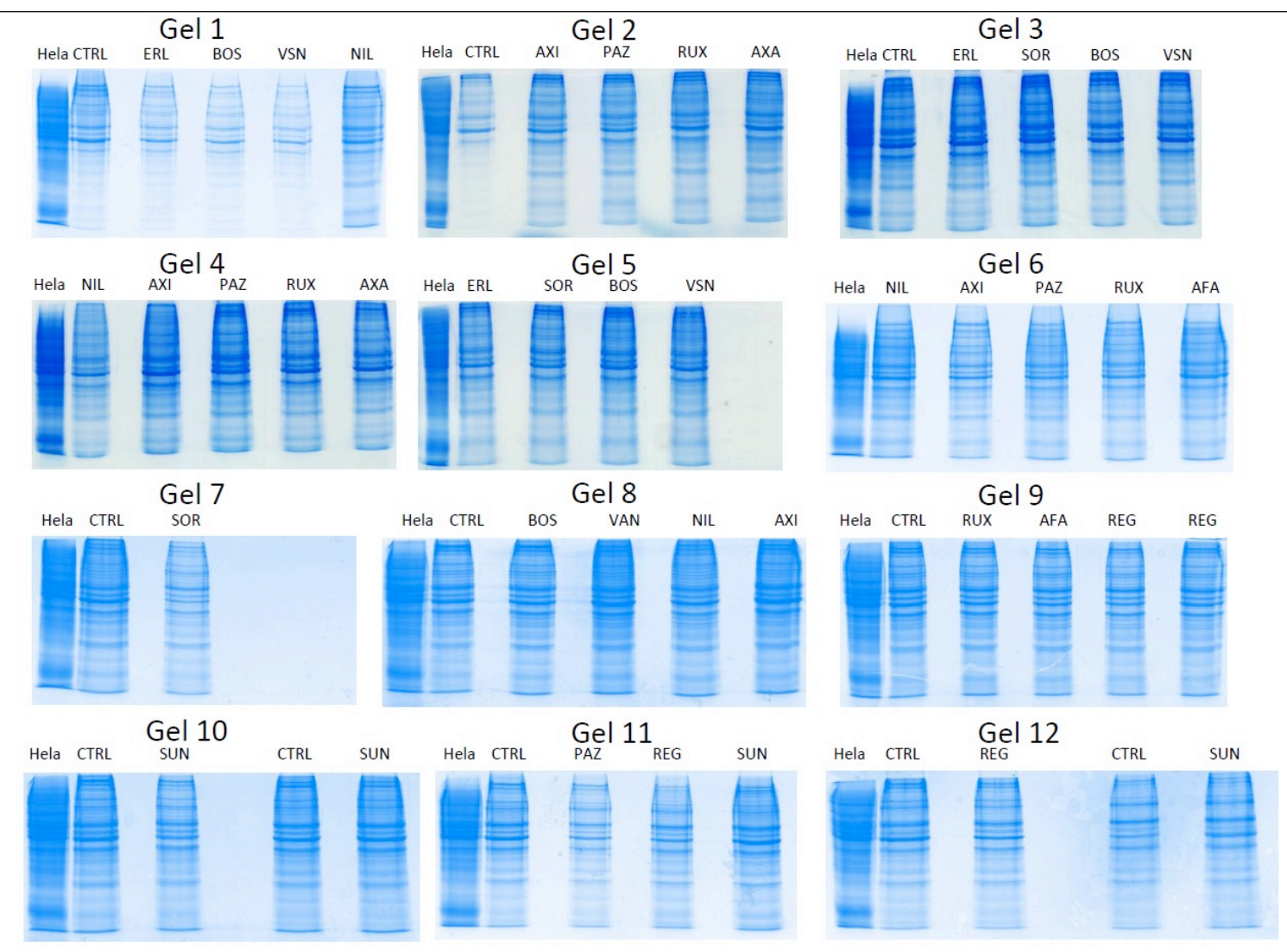

Supplementary Figure 1. Examples of protein quantification via SDS-PAGE. Twenty five micrograms of HeLa cell proteins was loaded along with the proteins recovered from the KI-drug treated cell line A and separated on 10\% SDS-PAGE gels. The gel was stained with CBB and the densities of the CBB stain from all lanes are measured. The protein CBB densities in drug-treated samples were compared to that of the HeLa cells, and the protein amounts in each sample was then estimated as described in Supplementary Table 2. 
bioRxiv preprint doi: https://doi.org/10.1101/2020.02.26.966606; this version posted February 26, 2020. The copyright holder for this preprint (which was not certified by peer review) is the author/funder, who has granted bioRxiv a license to display the preprint in perpetuity. It is made available under aCC-BY-NC-ND 4.0 International license.
CTRL.A.38.1.8 vs CTRL.A.38.1.10 CTRL.B.23.1.1 vs CTRL.B.23.1.2

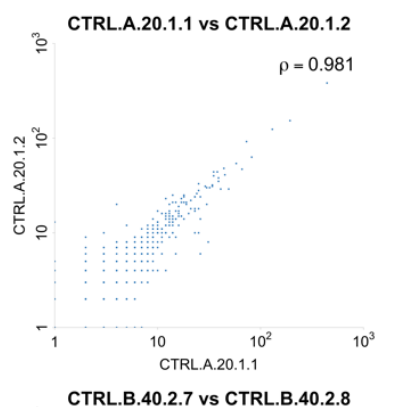

CTRL.B.40.2.7 vs CTRL.B.40.2.8
$\rho=0.965$
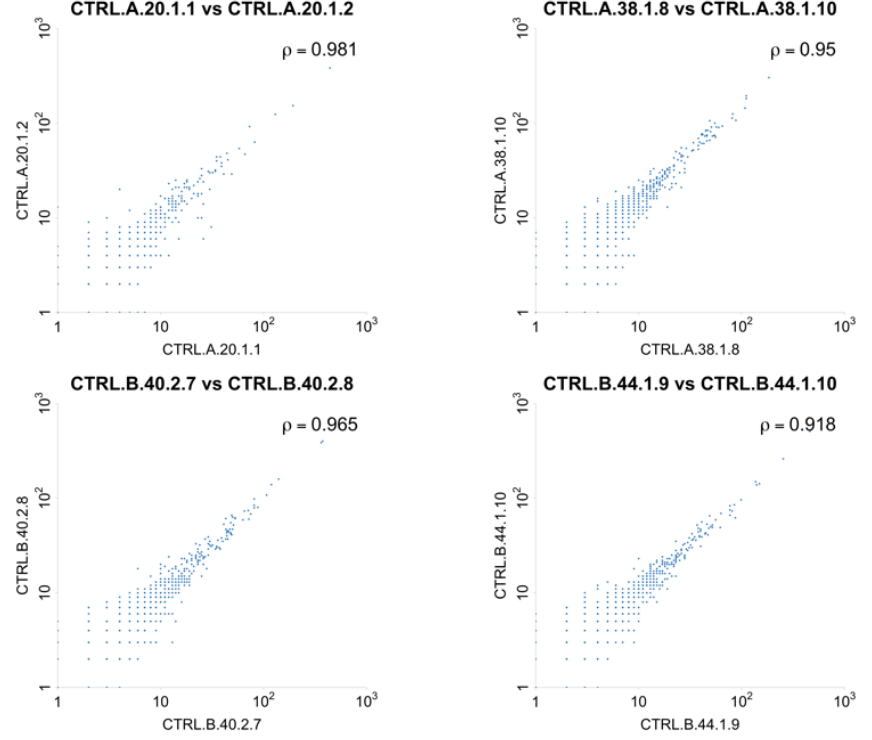

CTRL.B.50.1.16 vs CTRL.B.50.1.17
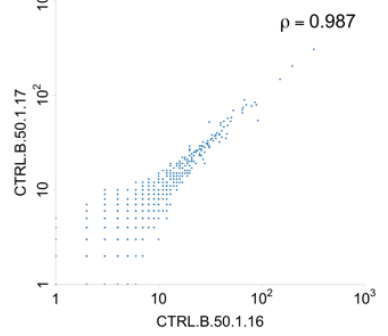

CTRL.D.39.1.3 vs CTRL.D.39.1.13

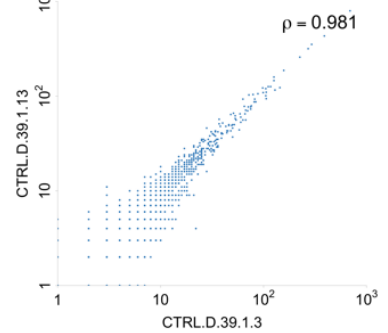

\% CTRL.D.42.1.8 vs CTRL.D.42.1.9

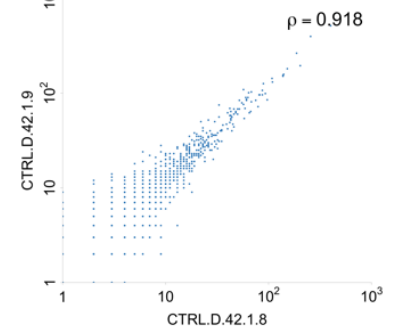

CTRL.E.41.2.9 vs CTRL.E.41.2.11

$\rho=0.982$
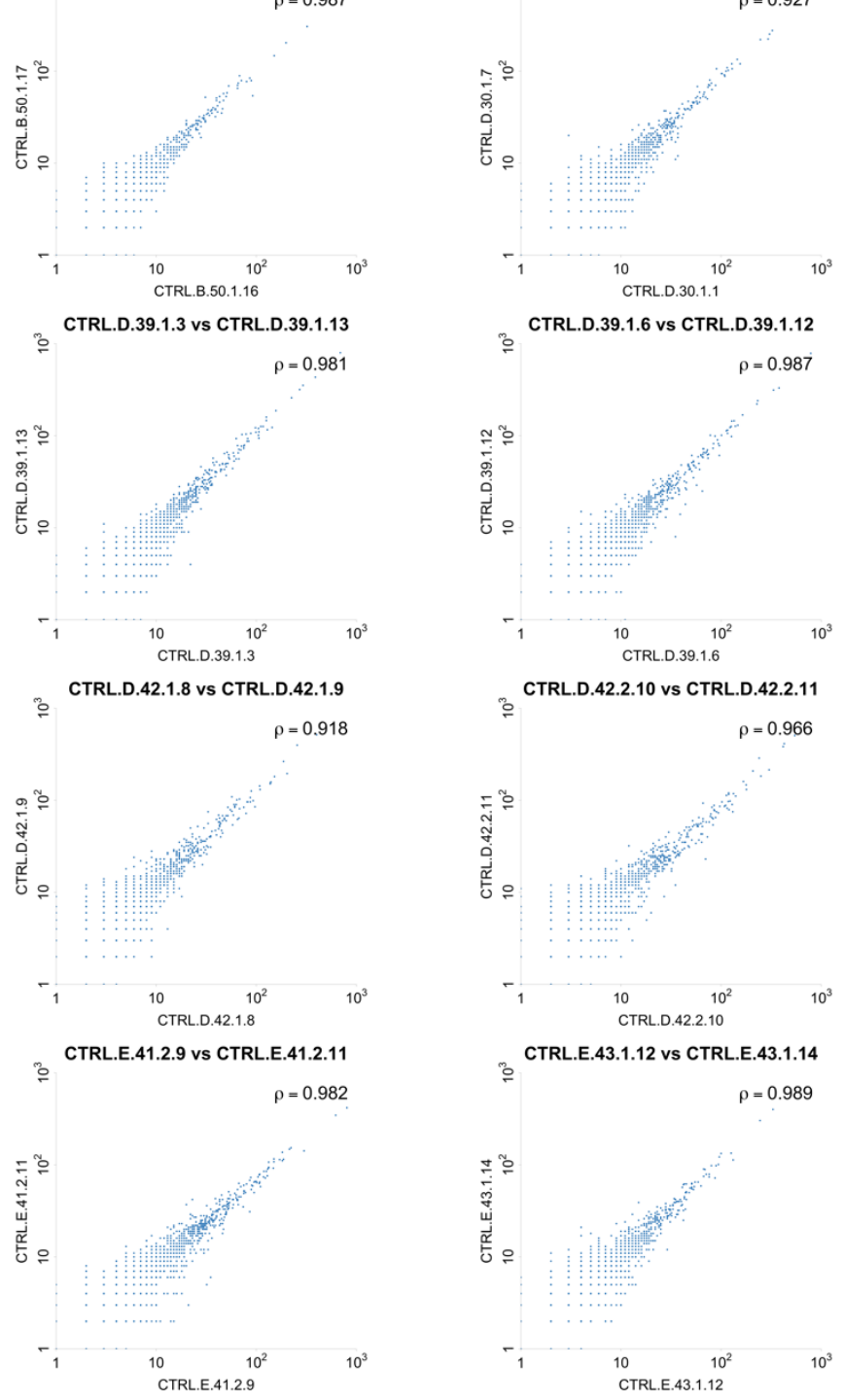

\% CTRL.B.44.1.9 vs CTRL.B.44.1.10

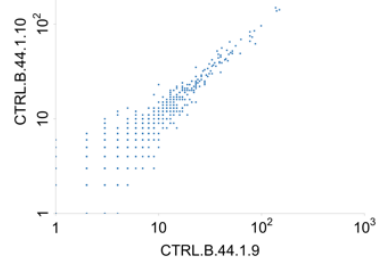

CTRL.D.30.1.1 vs CTRL.D.30.1.7

CTRL.D.39.1.6 vs CTRL.D.39.1.12

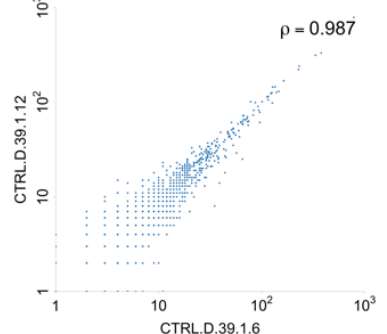

CTRL.D.42.2.10 vs CTRL.D.42.2.11

$\rho=0.966$

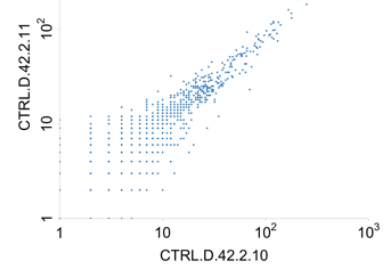

CTRL.E.43.1.12 vs CTRL.E.43.1.14

$\rho=0.989$

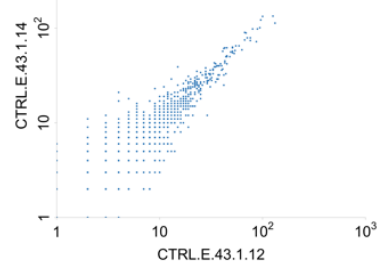

$\rho=0.981$

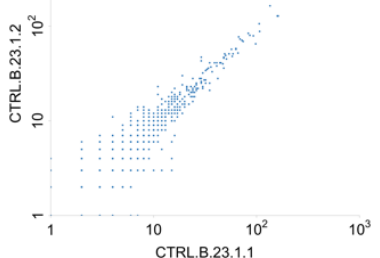

CTRL.B.44.2.11 vs CTRL.B.44.2.12

$\rho=0.966$

CTRL.B.40.1.5 vs CTRL.B.40.1.6

$\rho=0.966$

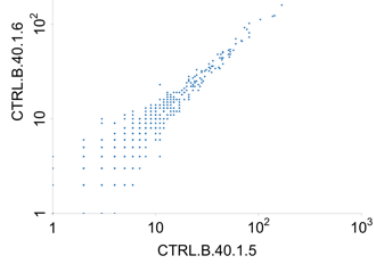

CTRL.B.46.1.13 vs CTRL.B.46.1.15

$\rho=0.977$

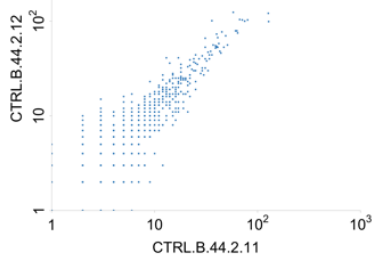

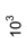

CTRL.D.39.1.3 vs CTRL.D.39.1.6

$\rho=0.98$

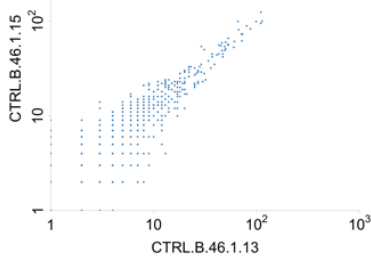

CTRL.D.39.1.3 vs CTRL.D.39.1.12

$\rho=0.983$

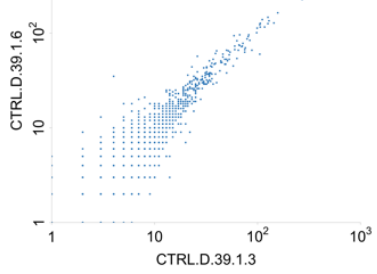

CTRL.D.39.1.6 vs CTRL.D.39.1.13

$\rho=0.986$

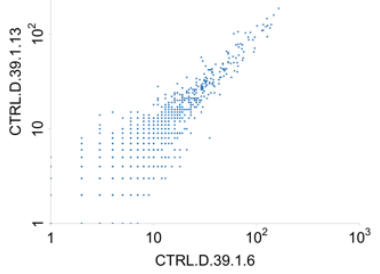

CTRL.E.37.1.5 vs CTRL.E.37.1.6

$\rho=0.965$

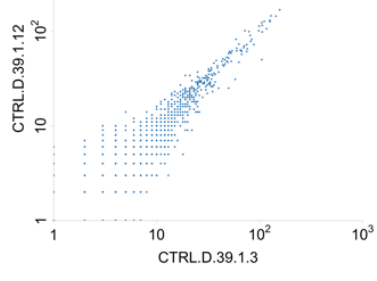

CTRL.D.39.1.12 vs CTRL.D.39.1.13 $\rho=0.977$

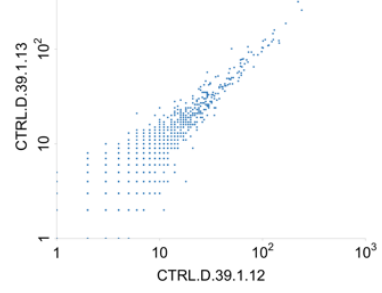

CTRL.E.41.1.8 vs CTRL.E.41.1.10

$\rho=0.973$

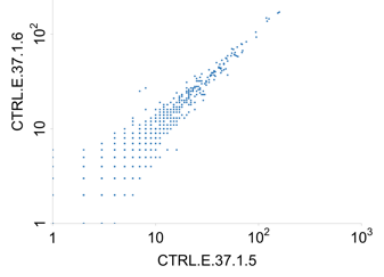

CTRL.E.45.1.15 vs CTRL.E.45.1.17

$\rho=0.986$

웅

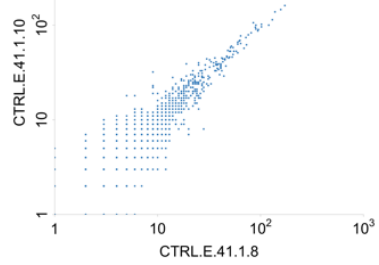


bioRxiv preprint doi: https://doi.org/10.1101/2020.02.26.966606; this version posted February 26, 2020. The copyright holder for this preprint

(which was not certified by peer review) is the author/funder, who has granted bioRxiv a license to display the preprint in perpetuity. It is made available under aCC-BY-NC-ND 4.0 International license.

Supplementary Figure 2. Reproducibility of proteomic quantification for technical replicates. Comparison of normalized MS1 LFQ counts for two technical replicates of the same biological sample that was run on a different SDS-PAGE gel and processed for MS/MS analysis on a different day. Pearson correlation coefficients show strong agreement between multiple runs. 


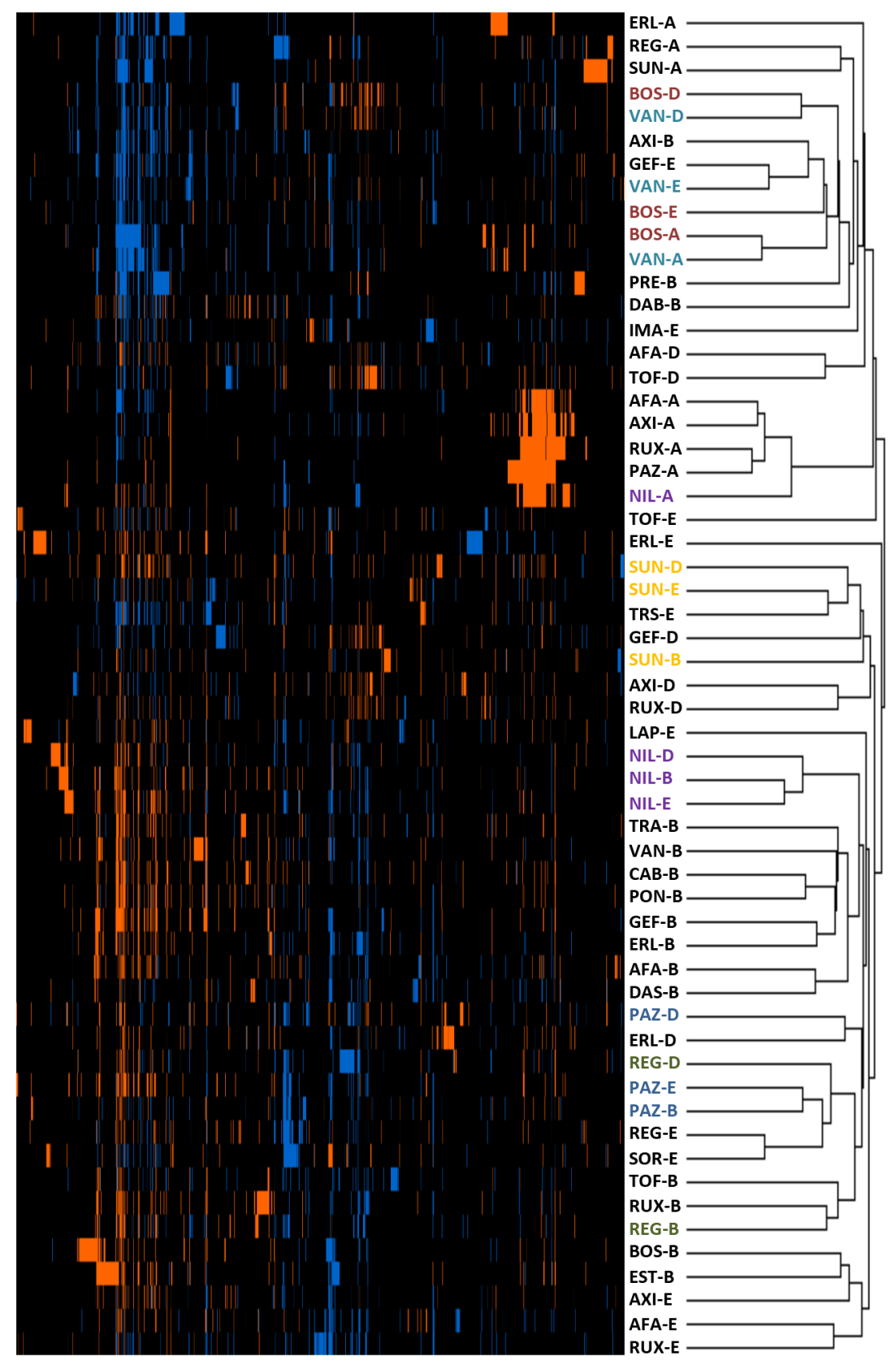

Supplementary Figure 3. Clustering of KI treated cardiomyocyte cell lines based on top $\mathbf{1 0 0}$ differentially expressed proteins. Cardiomyocyte cell lines treated with Kls that had small proteomic signatures clustered along the cell lines (A, B,D, E); however, those Kls that have large consistent differential proteomic signatures (e.g., SUN, NIL, PAZ, REG) clustered along the drugs regardless of the cell line. 


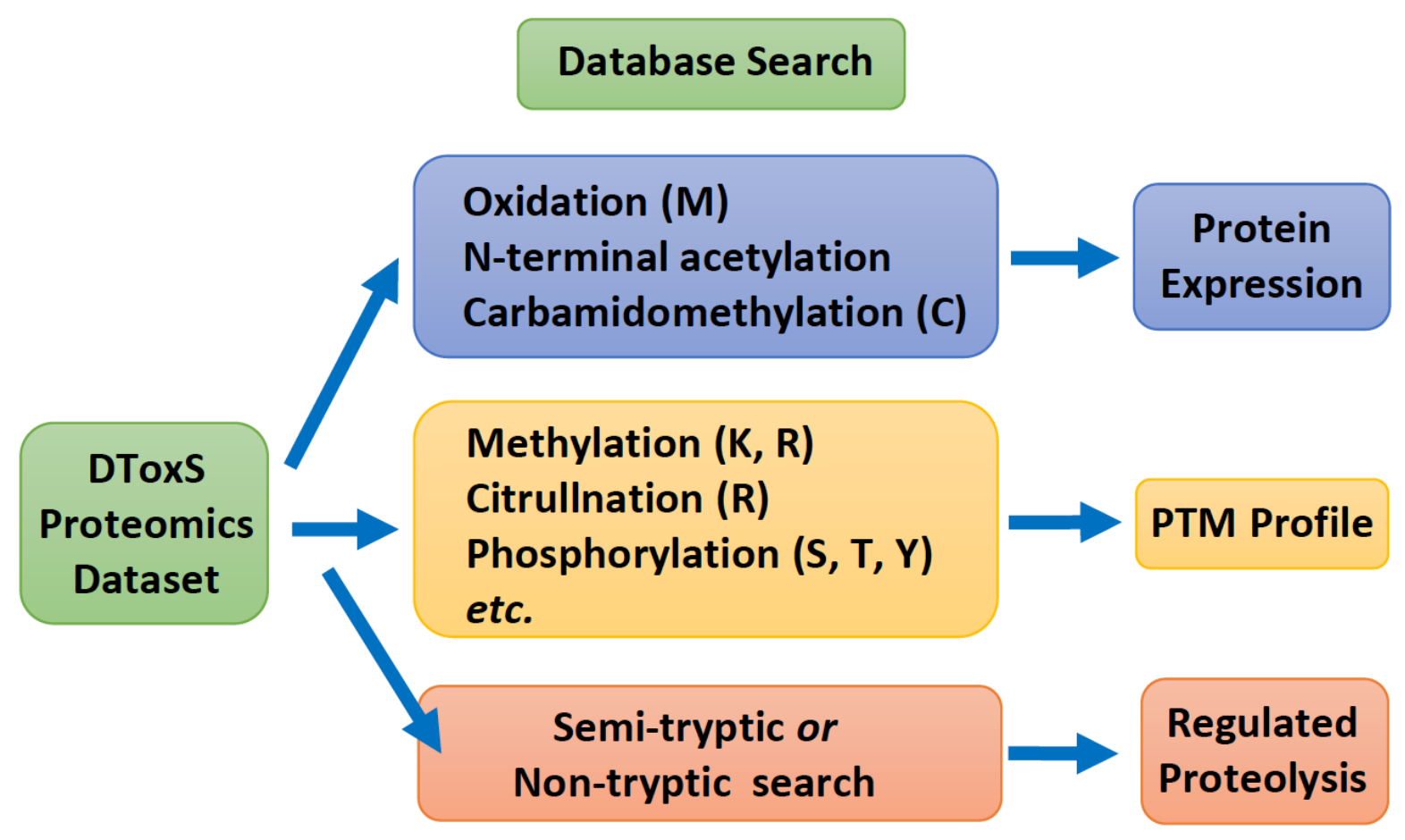

Supplementary Figure 4. Using the complementary proteomics search methods to identify drugregulated changes of proteins, PTMs and regulated proteolysis products. The DToxS proteomics dataset can be analyzed with different protein database search methods to obtain different pertinent information, including the changes of protein expression, PTMs and regulated proteolysis of specific peptides. 


\section{Supplementary Table 1: Drug-treated cell replicates in the DToxS proteomics dataset}

\begin{tabular}{|c|c|c|c|c|}
\hline Drug Treatment & PMC-A & PMC-B & PMC-D & PMC-E \\
\hline AFA & 3 & 4 & 4 & 5 \\
\hline AXI & 3 & 4 & 4 & 5 \\
\hline BOS & 5 & 4 & 4 & 5 \\
\hline CAB & 0 & 4 & 0 & 0 \\
\hline DAB & 0 & 4 & 0 & 0 \\
\hline DAS & 0 & 4 & 0 & 0 \\
\hline ERL & 3 & 4 & 4 & 2 \\
\hline EST & 0 & 4 & 0 & 0 \\
\hline GEF & 0 & 4 & 4 & 5 \\
\hline IMA & 0 & 0 & 0 & 3 \\
\hline LAP & 0 & 1 & 0 & 3 \\
\hline PAZ & 3 & 4 & 4 & 5 \\
\hline PON & 0 & 4 & 0 & 0 \\
\hline REG & 4 & 4 & 4 & 5 \\
\hline RUX & 3 & 4 & 4 & 5 \\
\hline SOR & 3 & 3 & 0 & 4 \\
\hline SUN & 3 & 4 & 4 & 6 \\
\hline TOF & 0 & 4 & 4 & 4 \\
\hline TRA & 0 & 4 & 0 & 0 \\
\hline TRS & 0 & 4 & 0 & 4 \\
\hline VAN & 5 & 4 & 4 & 5 \\
\hline VEM & 0 & 3 & 0 & 0 \\
\hline
\end{tabular}

* Four PromoCell cardiomyocyte-like cell lines; 35 separate experiments; 24 drugs ** Control (CTRL) samples: 13 biological replicates for PMC-A, 23 biological replicates for PMC-B, 13 biological replicates for PMC-D, and 22 biological replicates for PMC-E. 
bioRxiv preprint doi: https://doi.org/10.1101/2020.02.26.966606; this version posted February 26, 2020. The copyright holder for this preprint (which was not certified by peer review) is the author/funder, who has granted bioRxiv a license to display the preprint in perpetuity. It is made available under aCC-BY-NC-ND 4.0 International license.

\section{Supplementary Table 2. Examples of protein quantification via SDS-PAGE}
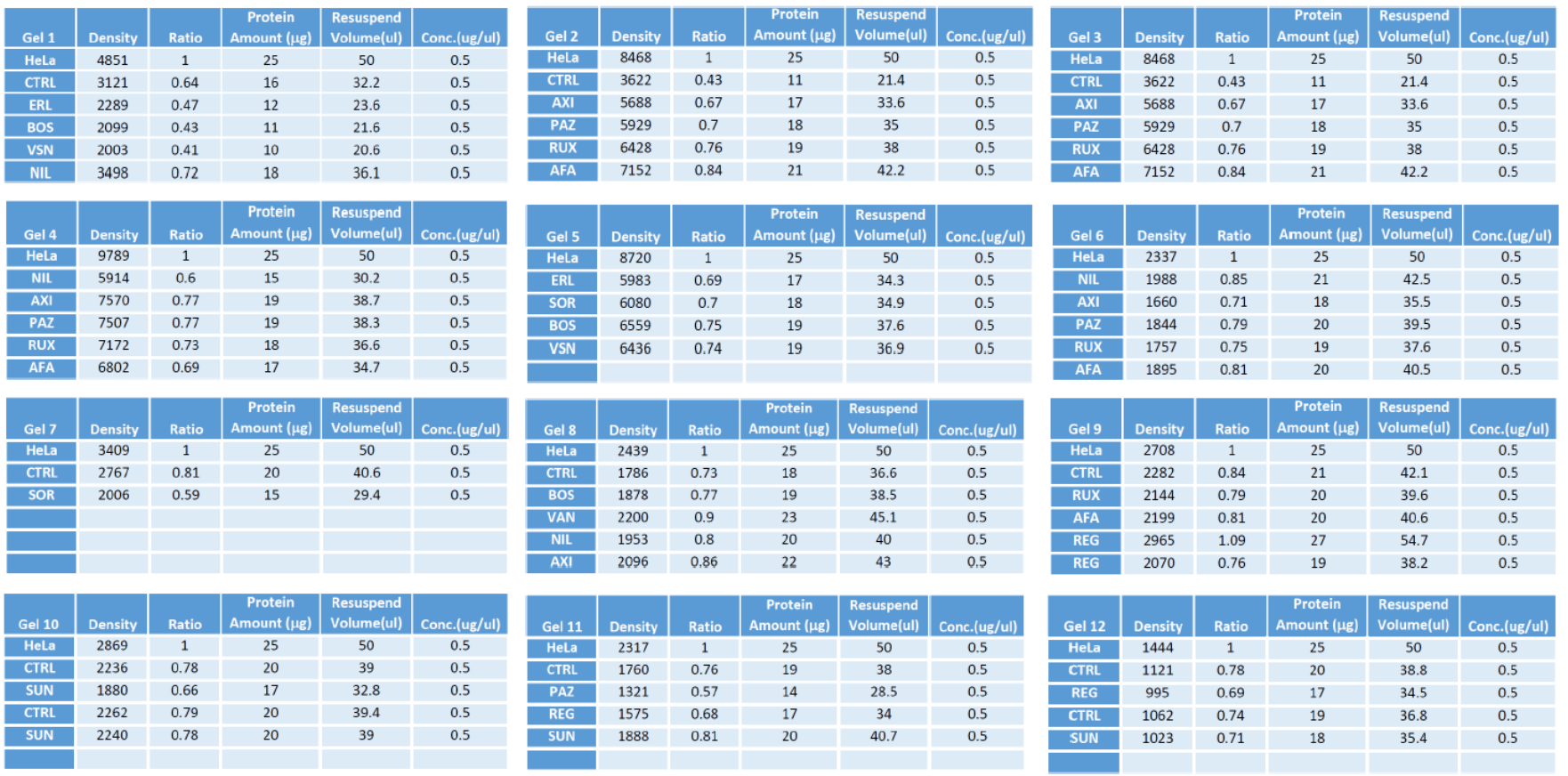

The CBB protein density of the entire lane for each sample lane was measured using ImageJ software $(\mathrm{NIH})$, and the protein amount for each drug-treated sample was calculated using the following equation: Protein amount $=$ HeLa cell protein amount $\times$ (Sample density / HeLa cell density). After in-gel tryptic digestions, the peptides were dissolved in HPLC solvents to obtain a final concentration of $0.5 \mu \mathrm{g} / \mathrm{mL}$, based on the calculated protein amounts. 